\title{
EVALUATION OF GROUP DECISION MAKING BASED ON GROUP PREFERENCES UNDER A MULTI-CRITERIA ENVIRONMENT
}

\author{
Wenshuai WU(D) 1,2, Zeshui XU(D22*, Gang KOU(D)3 \\ ${ }^{1}$ Guangdong Academy of Decision Sciences, Sun Yat-sen University, Guangzhou, \\ 510275, Guangdong, China. \\ ${ }^{2}$ Business School, Sichuan University, Chengdu, 610065, Sichuan, China \\ ${ }^{3}$ School of Business Administration, Southwestern University of Finance and Economics, \\ Chengdu, 611130, Sichuan, China
}

Received 15 November 2019; accepted 07 June 2020

\begin{abstract}
Arrow's impossibility theorem stated that no single group decision making (GDM) method is perfect, in other words, different GDM methods can produce different or even conflicting rankings. So, 1) how to evaluate GDM methods and 2) how to reconcile different or even conflicting rankings are two important and difficult problems in GDM process, which have not been fully studied. This paper aims to develop and propose a group decision-making consensus recognition model, named GDMCRM, to address these two problems in the evaluation of GDM methods under a multi-criteria environment in order to identify and achieve optimal group consensus. In this model, the ordinal and cardinal GDM methods are both implemented and studied in the process of evaluating the GDM methods. What's more, this proposed model can reconcile different or even conflicting rankings generated by the eight GDM methods, based on empirical research on two real-life datasets: financial data of 12 urban commercial banks and annual report data of seven listed oil companies. The results indicate the proposed model not only can largely satisfy the group preferences of multiple stakeholders, but can also identify the best compromise solution from the opinion of all the participants involved in the group decision process.
\end{abstract}

Keywords: group decision making, MCDM, consensus, group preferences.

JEL Classification: C44, C52, D81.

Online supplementary material: Supporting information for this paper is available as online supplementary material at: https://doi.org/10.3846/tede.2020.13378

\section{Introduction}

Nowadays, data have become a torrent flowing into various area of the global economy. A massive amount of data is collected from multiple data sources, such as transaction sale data, social media data, financial data, business data, etc. Data are a strategic asset, decision

*Corresponding author. E-mail: xuzeshui@263.net

Copyright (c) 2020 The Author(s). Published by Vilnius Gediminas Technical University

This is an Open Access article distributed under the terms of the Creative Commons Attribution License (http://creativecommons. org/licenses/by/4.0/), which permits unrestricted use, distribution, and reproduction in any medium, provided the original author and source are credited. 
makers are struggling to gain useful, valuable information, rules, patterns or business insights out of data for decision support. However, decision making process is an extremely complex process because of complexity of the systems considered and competitive conflicts of interest among multi-stakeholders (Ascough II et al., 2008; Wu et al., 2018, 2020). Individual decision greatly affects or even reduces the efficiency of decision-making. The reasons are as follows (Kim \& Ahn, 1997; Zhang, 2016; Wang et al., 2016): 1) Decision-making is often produced under time pressure, usually lacks of knowledge and data scenarios. 2) Many attribute characteristics are too difficult to quantify. 3) A single decision maker's expertise and information processing capabilities are often limited, especially in complex environments (Wu et al., 2012, 2018; Zhang, 2015). It is necessary to absorb group wisdom, based on the opinions of group members to minimize the impact of individual decision or personal prejudice.

Group decision making (GDM) has been widely recognized as a highly effective technique for improving the overall satisfaction of group members with final decisions (Yager, 1993; Wu et al., 2012; Tang \& Meng, 2019). The goal of GDM problem with multiple experts and several alternatives is to try to reach a consensus plan with full consideration of their opinions or preferences (Fu, 2008; Montserrat-Adell et al., 2019). Four ways of combining preferences into a consensus rating have been presented (Ishizaka \& Labib, 2011; Wu et al., 2018). With economic and social development, the growth of data has become increasingly faster, and the decision-making process has become increasingly more complex owing to great concern about multiple criteria, objectives or targets of a conflicting nature. GDM under a multi-criteria environment aims to address this GDM problem, and supports preferential decision to select the most satisfactory alternatives which have multiple conflicting goals or criteria in a group (Ma et al., 2010; Pérez-Arellano et al., 2019).

GDM under a multi-criteria environment involves multiple criteria, multiple stakeholders, and a finite number of alternatives, which can be interpreted as a MCGDM problem. In recent years, many scholars have conducted extensive research, application and discussion on MCGDM by multiple decision makers expressing their preference on multi-criteria, alternatives, etc and trying to find consensus solutions (Xu \& Shen, 2014; Li et al., 2017; Montserrat-Adell et al., 2019). In the case of MCGDM, a team of decision makers could be formed with the aim of bringing together individual preferences in the decision space based on their respective expertise, experience and knowledge, in order to form a more rational ranking of all options (Pang \& Liang, 2012; Chatterjee \& Bose, 2013; Montserrat-Adell et al., 2019). There is still a key and difficult issue which has not been fully studied in addressing MCGDM, namely how to identify and achieve optimal group consensus based on different preferences or opinions from different decision makers.

This paper is to propose a GDMCRM model for evaluation of GDM methods based on group preferences under a multi-criteria environment to identify and achieve optimal group consensus in order to make better decisions and improve business efficiency and productivity. The main contributions of this paper are that the proposed GDMCRM model is developed to effectively address these both issues: 1) how to evaluation of GDM methods, and 2) how to reconcile different or even conflicting rankings. Firstly, the evaluation of GDM methods involves more than one criterion, so this paper focuses on evaluation of GDM methods under a multi-criteria environment. Secondly, six GDM methods under a multi-criteria environment are selected and implemented by reading a significant amount 
of literature on group decision making. Besides, two other GDM methods, one belongs to graph method of the GDM methods, and the other belongs to the social choice method of GDM methods, are presented for comparative analysis. Furthermore, both the ordinal and cardinal GDM methods are considered in the process of evaluation of GDM methods under a multi-criteria environment. Finally, based on the $80-20$ rule, the GDMCRM method is developed and proposed to reconcile different or even conflicting rankings generated by the eight GDM methods, which can largely satisfy the group preferences of all the stakeholders involved in the group decision process.

The rest is arranged as follows: In Section 1, the related works are described. In Section 2, we introduce some research methodology, including the selected six MCGDM methods and two comparison GDM methods. The calculation steps of each method are given in detail. Next, in Section 3, a group decision-making consensus recognition model, named GDMCRM, is proposed and developed. In Section 4, two real-world datasets are applied to examine and verify the proposed model. Finally, the conclusions summarize the paper.

\section{Related works}

GDM aims to try to reach a consensus on a decision-making or a decision-related task (Kwok et al., 2002; Yan \& Ma, 2015). It consists of experts or stakeholders who are jointly responsible for identifying the problems, describing the nature, assessing potential solutions and developing implementation strategies (Chiclana et al., 2007; Liu et al., 2017; Shen et al., 2018; Xian et al., 2020). The GDM theory is developed from choice theory, utility theory, and behavioral decision theory. Among these, choice theory is the main theoretical basis in GDM. Choice theory, developed by Glasser (1998), is the explanation of human behavior based on internal motivation, including social choice theory and social welfare theory (Arrow, 1963; Sen, 1970). The underlying principle of utility theory is that decision makers know in advance the likelihood of all activities taking place and it can assign a value for each option (Von Neumann \& Morgenstern, 1944; Li et al., 2012). Behavioral decision theory focuses on the cognitive and subjective psychological processes of decision makers, which emphasizes the study of psychological analysis of individual decision-making behavior (Poulton, 1994).

GDM under a multi-criteria environment involves multiple criteria, multiple stakeholders, and a finite number of alternatives, which can be interpreted as an MCGDM problem. In recent years, the MCGDM has been widely studied, applied and discussed (Xu \& Shen, 2014; Xian et al., 2020), and it can address decision issues by decision makers expressing preferences on multi-criteria and can try to find a solution to reach a consensus (Li et al., 2017; Montserrat-Adell et al., 2019). MCGDM problems can be solved by generating a solution set of alternatives considering the preferences or opinion given by multi-experts (Srdjevic, 2007). In an MCGDM problem, a group of decision makers can be composed with the aim of achieving a more rational ranking of all the alternatives based on aggregating the individual preferences according to their respective expertise, experience and knowledge for a decision space (Pang \& Liang, 2012; Chatterjee \& Bose, 2013; Montserrat-Adell et al., 2019). There is still not a well-studied problem in addressing MCGDM, namely how to identify and achieve optimal group consensus based on different judgments and opinions from different decision makers. 
Our research focuses on evaluation of GDM methods under a multi-criteria environment in which the experts can fully express their opinions or preferences by considering the multi-criteria or even conflicting criteria of quantity and quality in real-life applications. Usually, GDM under a multiple criteria environment involves multi-criteria, multi-stakeholders, and a finite number of alternatives, which can be interpreted as multi-criteria group decision making. Several scholars have advanced some multi-criteria decision-making (MCDM) methods to address GDM problem under a multi-criteria environment (Montserrat-Adell et al., 2019). Beynon (2005) proposed a DS/AHP method based on MCDM as an effective technical method to deal with GDM problems. Gargallo et al. (2007) presented a Bayesian estimation program to evaluate the priority of analytical hierarchy process (AHP) in GDM. Dong et al. (2010) presented an AHP group decision-making consensus model under the row geometric mean prioritization method to address GDM problems. Yue (2011) proposed a GDM method using TOPSIS based on the weight of decision makers. Yue (2014) presented a TOPSIS-based GDM method in an intuitionistic fuzzy setting. Xian et al. (2016) developed and proposed a new method for multiple attribute group decision making for fuzzy numbers, named FEOWA. Filho and Morais (2018) proposed a group decision-making model based on ordered weighted distance OWD for distance aggregators to select a solution. Tang and Meng (2019) proposed linguistic intuitionistic fuzzy Hamacher aggregation operators to apply for group decision making. A new extension of the ordered weighted average (OWA) operator is presented and used in a GDM process for selection of the alternatives (Pérez-Arellano et al., 2019). Much research has focused on developing new algorithms or designing new models. However, there are situations in which different MCDM methods can produce different or even conflicting rankings (Peng et al., 2011; Kou et al., 2012; Wu et al., 2018, 2020), and how to reconcile these different or even conflicting rankings in GDM becomes an important research issue which has not yet been fully studied and investigated.

Acquiring consensus is an important measure of the success of GDM (Moreno-Jiménez et al., 2008; Wu, 2017). According to modern social choice theory, the result of the group's decision will never satisfy every member of the group (Banerjee, 1994). Furthermore, Arrow's impossibility theorem (1963) stated that no single GDM method is perfect. Thus, how to evaluate and select GDM methods based on group preferences under a multi-criteria environment are still a significant task and a challenging problem. In addition, GDM methods include ordinal and cardinal GDM methods (Xu \& Chen, 2007). Therefore, both ordinal and cardinal GDM methods must be considered when GDM methods under a multi-criteria environment are evaluated and analyzed, which further increases this research depth and scientific nature.

The essence of MCGDM problems is how to aggregate individual preferences or opinion into a consensus achievement reasonably and effectively. Thus, in this paper, how to identify and achieve optimal group consensus based on different judgments and opinions from different decision makers is our focus, and must be addressed. In this paper, we try to integrate different or even inconsistent conflicts among the evaluation performance of MCGDM methods with different criteria and alternatives by aggregating individual preferences or opinion into a consensus achievement reasonably and effectively. 


\section{Research methodology}

MCGDM combines GDM and MCDM methods, and has been widely recognized as an effective technical approach to increase overall satisfaction for the final decision in a group of members (Yager, 1993; Dong et al., 2018). MCDM is the study of methods which concerns multiple alternatives and multiple criteria (Fu, 2008; Gou et al., 2018). The most feasible alternative can be identified, based on reliable indicators, from a set of alternatives (Wu et al., 2012; Liao et al., 2018). MCDM can provide compromise alternatives involving a number of criteria and alternatives, which includes AHP, TOPSIS, ordered weighting averaging (OWA), etc. (Yoon \& Hwang, 1995). In this section, firstly, based on MCDM methods, by reading a significant amount of literature on GDM, six MCGDM methods under a multi-criteria environment are introduced and presented. Secondly, two other GDM methods are presented and proposed to facilitate a comparison with the six aforementioned MCGDM methods. In the eight introduced GDM methods, AHP for group decision making, TOPSIS for group decision making, weighted arithmetic mean (WAM) for group decision making, and weighted geometric mean (WGM) for group decision making are the cardinal GDM methods. Combined weighted arithmetic average (CWAA) for group decision making, combined weighted geometric average (CWGA) for group decision making, the three-dimensional leg-mark selected location method (TDLMSLM), and the Borda count method are the ordinal GDM methods. In addition, three experts in the field of risk assessment, including a risk-preference expert, a risk-averse expert and a risk-neutral expert, are selected and invited according to their authority, experience, expertise, and risk preference. To facilitating understanding of CWAA and CWGA, the concept and formula of OWA and OWGA are firstly introduced in detail.

\subsection{MCGDM methods}

\subsubsection{AHP for group decision making}

The AHP was proposed in the 1970s by Saaty, and has been considered as an important and effective technology of solving many types of decision problems of choice and prioritization such as in management science, economics, sociology and politics (Saaty, 1978, 1979, 1986, 2003). According to the pairwise comparison value of a group of objects, it can obtain a corresponding priority vector from the decision makers to explain the preference information (Yu, 2002). Pairwise comparison is the key content of AHP, which is completed by experts (Peng et al., 2011; Kou \& Ergu, 2016; Wu et al., 2018).

AHP allows GDM, in which a complex problem can be decomposed into a hierarchy according to the experience and knowledge of group members, and solved it by following the AHP process (Saaty, 1990; Jabbarzadeh, 2018; Wu et al., 2018). In this article, AHP for group decision making model has three steps. Firstly, the weight of each expert can be determined according to the authority, experiences, expertise, and risk preference of each expert. Secondly, a corresponding priority vector of each expert is elicited and determined by explaining the preference information according to the pairwise comparison value of a group of objects. Finally, group consensus is integrated and obtained by weighted geometric mean, and the corresponding alternative priorities can be elicited by the AHP for group decision making. 


\subsubsection{TOPSIS for group decision making}

TOPSIS, one of the most classical MCDM methods, was originally proposed by Hwang and Yoon (1981) to sort the alternatives for addressing the decision making problem under a multi-criteria environment. It is based on the principle that the chosen scheme should be the shortest distance from the positive ideal solution and the farthest distance from the negative ideal solution (Chen \& Hwang, 1992; Liang et al., 2018). All alternatives can be sorted, based on their closeness to the ideal solution. The calculation steps are as follows (Olson, 2004; Jahanshahloo et al., 2006; Shen et al., 2018):

(1) Generate the normalized decision matrix $A$. The normalized value $a_{i j}$ can be generated as:

$$
a_{i j}=\frac{x_{i j}}{\sqrt{\sum_{i=1}^{m}\left(x_{i j}\right)^{2}}}(1 \leq i \leq m, 1 \leq j \leq n) .
$$

(2) Obtain the weighted normalized decision matrix of each expert:

$$
D^{k}=\left(a_{i j}{ }^{*} w_{j}\right)(1 \leq i \leq m, 1 \leq j \leq n),
$$

where $w_{j}$ is the weight of the $j_{\text {th }}$ criterion, determined by AHP, and $\sum_{j=1}^{n} w_{j}=1$.
(3) Calculate the group weighted normalized decision matrix $D$ :

$$
D=\sum_{k=1}^{p} W^{k} D^{k}(1 \leq k \leq p),
$$

where $W^{k}$ is the weight of the $k_{\mathrm{th}}$ expert, determined by the authority, experiences, expertise, and risk preference of each expert, and $\sum_{k=1}^{p} W^{k}=1$.

(4) Calculate the group ideal solution $V^{*}$ and the group negative ideal solution $V^{-}$:

$$
\begin{aligned}
& V^{*}=\left\{v_{1}^{*}, v_{2}^{*}, \cdots, v_{n}^{*}\right\}=\left\{\left(\max _{i} v_{i j} \mid j \in J\right), \quad\left(\min _{i} v_{i j} \mid j \in J^{\prime}\right)\right\}, \\
& V^{-}=\left\{v_{1}^{-}, v_{2}^{-}, \cdots, v_{n}^{-}\right\}=\left\{\left(\min _{i} v_{i j} \mid j \in J\right), \quad\left(\max _{i} v_{i j} \mid j \in J^{\prime}\right)\right\} .
\end{aligned}
$$

(5) Compute the separation measures, according to the $m$-dimensional Euclidean distance:

$$
\begin{aligned}
& S_{i}^{+}=\sqrt{\sum_{j=1}^{n}\left(V_{i}^{j}-V^{*}\right)^{2}} \quad(1 \leq i \leq m, 1 \leq j \leq n), \\
& S_{i}^{-}=\sqrt{\sum_{j=1}^{n}\left(V_{i}^{j}-V^{-}\right)^{2}} \quad(1 \leq i \leq m, 1 \leq j \leq n) .
\end{aligned}
$$

(6) Calculate the relative closeness to the group ideal solution:

$$
Y_{i}=\frac{S_{i}^{-}}{S_{i}^{+}+S_{i}^{-}}(1 \leq i \leq m),
$$

where the closer $Y_{i}, Y_{i} \in(0,1)$ is to 1 , the closer the alternative is to the ideal solution. 
(7) Rank the group preference order:

The larger the $Y_{i}$ value, the better the alternative is.

\subsubsection{WAM}

Generally, in the complex decision-making problems, the most commonly used operator to aggregate criteria is the classical WAM (Marichal, 2001). It is the simplest and most widely applied group preference aggregation technology for evaluating schemes. The calculation formula (Marichal, 2001; Chwolka \& Raith, 2001) is as follows:

$$
\operatorname{WAM}\left(a_{1}, a_{2} \ldots, a_{n}\right)=\sum_{i=1}^{n} w_{i} a_{i},
$$

where $w=\left(w_{1}, w_{2} \ldots w_{n}\right)$ is the weighted vector of the $n$ objects $a_{i}(1 \leq i \leq n)$, and $w_{i} \in[0,1]$, $\sum_{i=1}^{n} w_{i}=1$.

In this Section, the principle of WAM for group decision making is as follows: the corresponding priority vector of each expert, produced by AHP, is considered as the $n$ objects. The weight of each expert, determined according to authority, experiences, expertise, and risk preference, is considered as the aggregation-weighted vector in group decision making. The index weights obtained by AHP are considered as its weighted vector of the $n$ objects.

\subsubsection{WGM}

WGM is a group preference aggregation method often used in AHP (Xu, 2000). The WGM is very important for studying geometric structures and it aims to consider the problem that geometric mean of $n$ operators can be extended to that of the WGM (Jung et al., 2010). The calculation formula (Xu, 2000; Jung et al., 2010) is as follows:

$$
\operatorname{WGM}\left(a_{1}, a_{2} \ldots, a_{n}\right)=\prod_{i=1}^{n} a_{i}^{w_{i}},
$$

where $w=\left(w_{1}, w_{2} \ldots w_{n}\right)$ is the weighted vector of the $n$ objects $a_{i}(1 \leq i \leq n)$, and $w_{i} \in[0,1]$, $\sum_{i=1}^{n} w_{i}=1$.

In this Section, the principle of WGM for group decision making is as follows: the relative closeness to the ideal solution of each expert, produced by TOPSIS, is considered as the $n$ objects. The weight of each expert, determined according to authority, experiences, expertise, and risk preference, is considered as the aggregation-weighted vector in group decision making. The index weights obtained by AHP are considered as its weighted vector of the $n$ objects.

\subsubsection{OWA}

OWA operator, introduced by Yager, is a very important aggregation operator, which provides a way to aggregate the inputs which lies between the Max and Min operators (Yager, 1988). The basic principle is a reorder step in which the input parameters are reordered in descending order (Yager, 1988; Chang \& Cheng, 2011). The OWA operator has been widely 
used in many fields, such as decision-making (Yager, 1993; Cutello \& Montero, 1994), expert systems (O'Hagan, 1998), and market research (Yager et al., 1994). The OWA operator can obtain the optimal ordering of the alternatives according to the reordering steps of weighted vectors in the decision process of aggregation as follows (Chang \& Cheng, 2011; Blanco-Mesa et al., 2019):

Definition 1: An $n$ dimension OWA operator (Yager, 1988; Blanco-Mesa et al., 2019) can be a mapping $F: R^{n} \rightarrow R$, which has an associated $n$ weighting vector $w=\left(w_{1}, w_{2}, \ldots w_{n}\right)^{T}$, and has the property of $\sum_{i=1}^{n} w_{i}=1, \forall w_{i} \in[0,1], i=1,2, \ldots n$, such that

$$
\operatorname{OWA}_{w}\left(a_{1}, a_{i}, \cdots a_{n}\right)=\sum_{j=1}^{n} w_{j} b_{j}(1 \leq i \leq n ; 1 \leq j \leq n),
$$

where $b_{j}$ is the $j_{\text {th }}$ maximum element of the $n$ aggregated object sets $a_{i}(1 \leq i \leq n)$, the weight $w_{j}$ is not related to the value of any aggregated object $a_{i}$, but it's related to the ordinal position of $b_{j}$.

\subsubsection{OWGA}

The OWGA operator is a very important aggregation operator considered and characterized by Chiclana et al. to design multiplication decision-making models (Chiclana et al., 2000). It is based on the geometric mean and OWA operator (Xu \& Da, 2002a). The definition and calculation steps are as follows:

Definition 2: An $n$ dimension OWGA operator (Chiclana et al., 2000; Xu \& Da, 2002a) can be a mapping $F: R^{n} \rightarrow R$, which has an associated $n$ weighting vector $w=\left(w_{1}, w_{2}, \ldots w_{n}\right)^{T}$, and has the property of $\sum_{i=1}^{n} w_{i}=1, \forall w_{i} \in[0,1], i=1,2, \ldots n$, such that

$$
\mathrm{OWGA}_{w}\left(a_{1}, a_{i}, \cdots a_{n}\right)=\prod_{j=1}^{n} b_{j}^{w_{j}}(1 \leq i \leq n ; 1 \leq j \leq n)
$$

where $b_{j}$ is the $j_{\text {th }}$ maximum element of the $n$ aggregated object sets $a_{i}(1 \leq i \leq n)$, the weight $w_{j}$ is not related to the value of any aggregated object $a_{i}$, but it's related to the ordinal position of $b_{j}$.

\subsubsection{CWAA}

The CWAA operator is a very important group aggregation operator on the base of the OWA operator. The CWAA operator combines the characteristics of the OWA operator, considering not only the position of evaluation information, but also the importance of evaluation information of each expert in the whole expert group.

Definition 4: An $n$ dimension CWAA operator ( $\mathrm{Su}$ et al., 2011) can be a mapping $F: R^{n} \rightarrow R$, which has an associated $n$ weighting vector $w=\left(w_{1}, w_{2}, \ldots w_{n}\right)^{T}$, and has the property of $\sum_{i=1}^{n} w_{i}=1, \forall w_{i} \in[0,1], i=1,2, \ldots n$. The calculation formula is as follows: 


$$
\mathrm{CWAA}_{\omega, w}\left(a_{1}, a_{i}, \cdots, a_{n}\right)=\sum_{j=1}^{n} w_{j} b_{j}(1 \leq i \leq n ; 1 \leq j \leq n),
$$

where $w=\left(w_{1}, w_{2}, \ldots w_{n}\right)^{T}$ is a weighted vector related to OWA, which has the property of $\sum_{i=1}^{n} w_{i}=1, \forall w_{i} \in[0,1], i=1,2, \cdots n . b_{j}$ is the $j_{\text {th }}$ maximum element in a group of data $\left(n \omega_{1} a_{1}, n \omega_{2} a_{2}, \ldots, n \omega_{i} a_{i}\right)$, and $\omega=\left(\omega_{1}, \omega_{2}, \cdots \omega_{n}\right)^{T}$ is a weighted vector of data group $\left(a_{1}, a_{2}, \cdots a_{n}\right), n$ is a balance factor.

\subsubsection{CWGA}

The CWGA operator is a very important group aggregation operator on the base of the OWGA operator. The CWGA operator combines the characteristics of the OWGA operator, considering not only the position of evaluation information, but also the importance of evaluation information of each expert in the whole expert group.

Definition 4: An $n$ dimension CWGA operator (Xu \& Da, 2002b) can be a mapping $F: R^{n} \rightarrow R$, which has an associated $n$ weighting vector $w=\left(w_{1}, w_{2}, \ldots w_{n}\right)^{T}$, and has the property of $\sum_{i=1}^{n} w_{i}=1, \forall w_{i} \in[0,1], i=1,2, \ldots n$. The calculation formula is as follows:

$$
\operatorname{CWGA}_{\omega, w}\left(a_{1}, a_{2}, \cdots a_{n}\right)=\prod_{j=1}^{n} b_{j}^{w_{j}} \quad(1 \leq i \leq n ; 1 \leq j \leq n)
$$

where $w=\left(\mathrm{w}_{1}, w_{2}, \ldots w_{n}\right)^{T}$ is a weighted vector related to CWGA, which has the property of $\sum_{\mathrm{j}=1}^{n} w_{j}=1, \forall w_{j} \in[0,1], j=1,2, \cdots n . b_{j}$ is the $j_{\text {th }}$ maximum element in a group of data $\left(a_{1}^{n \omega_{1}}, n a_{2}^{n \omega_{2}}, \ldots, n a_{n}^{n \omega_{n}}\right)$, and $\omega=\left(\omega_{1}, \omega_{2}, \cdots \omega_{n}\right)^{T}$ is an exponential weighting vector of data group $\left(a_{1}, a_{2}, \cdots a_{n}\right), n$ is a balance factor.

\subsection{Other GDM methods for comparative analysis}

\subsubsection{Three-dimensional leg-mark selected location method}

In this paper, a three-dimensional leg-mark selected location method (TDLMSLM) (Wu \& Peng, 2016), which belongs to graph method of the GDM methods, based on expert prioritization, is applied for identifying and facilitating group consensus according to the established a three-dimensional leg-mark coordinate system. It has the characteristics of simplicity and calculation, and it only needs a little bit of information about each expert's individual preference ranking (Wu \& Peng, 2016).

Assume there are $A=\left\{A_{1}, A_{2}, \cdots A_{i} \cdots A_{m}\right\}(1 \leq i \leq m)$ alternatives and three experts, $\mathrm{DM}_{1}$, $\mathrm{DM}_{2}$, and $\mathrm{DM}_{3}$. Let $A_{p q r} \in A(1 \leq p \leq m, 1 \leq q \leq m, 1 \leq r \leq m)$, where $m$ is the number of alternatives, and $\mathrm{p}, \mathrm{q}$ and $\mathrm{r}$ are the axes of three-dimensional leg-mark coordinate system respectively, corresponding to DM1, DM2 and DM3 respectively. That is to say, the number of the $\mathrm{DM}_{1}$ axis represents $p$ of $A_{p g r}$, similarly, the number of the $\mathrm{DM}_{2}$ axis represents $q$ of $A_{p g r}$, and the number of the $\mathrm{DM}_{3}$ axis represents $r$ of $A_{p g r}$ (Wu \& Peng, 2016). Therefore, each $A_{p g r}$ has 
a unique corresponding position in the three-dimensional leg-mark coordinate system $(\mathrm{Wu}$ \& Peng, 2016). The calculation steps are as follows (Wu \& Peng, 2016):

$$
\begin{aligned}
& F_{a_{i}}(p, q, r)=(p+q+r)+\frac{|p-q|+|p-r|+|q-r|}{10^{\alpha}}+\frac{p}{10^{2 \alpha}}(1 \leq i \leq m), \\
& \alpha= \begin{cases}1, & \text { when } 1 \leq m<10, \\
2, & \text { when } 10 \leq m<100, \\
3, & \text { when } 100 \leq m<1000 .\end{cases}
\end{aligned}
$$

The group consensus order can be easily obtained according to the value of $F$ based on the rules presented by $\mathrm{Wu}$ and Peng (2016).

In this method, the relative closeness to the ideal solution of each expert, produced by TOPSIS, is considered as the each expert's individual preference ranking.

\subsubsection{Borda count method}

The Borda count method belongs to the social choice method of GDM methods, and it is a single winner election method, based on location and preference, which marks that the development of voting theory has made important achievements. The Borda count can produce the winner of an election depending on the number of votes given to each candidate. For each vote, the scores corresponding to the number of candidates are allocated. Once the count is completed, the most popular option or candidate is the winner (Benjamin, 2002). The method can be applied for electing members of the Parliament of Nauru (Emerson, 2007).

In this method, suppose that $\mathrm{m}$ candidates are selected. Each alternative receives 0 point for the last place vote, 1 point for the next-to-last point vote, etc., until $\mathrm{m}-1$ point for each first place vote. Finally, each candidate's score is totaled. The alternative with the highest total score wins the election and is declared the result of social choice (Srdjevic, 2007). The function of the Borda count method is considered as follows (Xu \& Chen, 2007):

$$
f_{B}(x)=\sum_{y \in A \backslash\{x\}} N\left(x \succ_{i} y\right) .
$$

The alternative with the highest $f_{B}(x)$ value can be selected as the winner.

\section{Proposed model}

In this section, a group decision making consensus recognition model (named GDMCRM) is proposed to address different or even conflicting rankings among GDM methods under a multi-criteria environment. The goal of this Section is to identify an optimal ranking scheme according to the decision preferences of all the participants involved in the decision making problem. It must be emphasized that each MCGDM ranking represents the group preference of the decision makers. The proposed model can be separated into two stages:

Stage 1: Evaluate methods. This Stage is to evaluate GDM methods under a multi-criteria environment. By reading a significant amount of literature on GDM, six GDM methods under a multi-criteria environment are selected. Besides, two other GDM methods are presented and proposed to make a comparison with MCGDM methods: TDLMSLM be- 
longs to graph method of the GDM methods, and the Borda count method belongs to the social choice method of GDM methods. The calculation steps and processes of the eight GDM methods are given and presented in detail. Furthermore, AHP for group decision making, TOPSIS for group decision making, WAM for group decision making, and WGM for group decision making are the cardinal GDM methods, and CWAA for group decision making, CWGA for group decision making, TDLMSLM, and the Borda count method are the ordinal GDM methods.

Stage 2: Achieve consensus. This Stage is to identify and achieve an optimal ranking scheme by a consensus recognition model (CRM), based on group preferences of evaluation results of GDM methods generated in Stage 1. The CRM model includes three steps as follows (Wu et al., 2020):

Step 1: Establish two sorted alternative sets considered as a top position and a bottom position according to the rankings of the eight GDM methods.

It is common knowledge that the 80-20 rule originated in Pareto in 1896, the principle has found that in most countries about $80 \%$ of wealth is controlled by a consistent minority which is about $20 \%$ of the population (Franz, 1936). The $80-20$ rule has been wildly applied and extended in the fields of sociology, economics, management, quality control, etc (Renato, 1983; Morais \& Almeida, 2012). The 80-20 rule focuses on the most important positions of the rankings associated with the number of observations. Truth is often in the hands of a few. Thus, the sorting set of alternatives can be broken up two sections: the top $1 / 5$ of the alternatives can be sorted in a top position, which represents satisfactory rankings from the opinion of all the participants involved in the GDM process. And the bottom of $1 / 5$ can be sorted in a bottom position, which represents dissatisfactory rankings from the opinion of all the participants involved in the GDM process. The element sorted in a top position can be calculated as follows:

$$
x=n \times 1 / 5 \text {, }
$$

where $n$ is the total number of the sorted alternatives. For instance, if $n=7$, then $x=7 \times 1 / 5=1.4 \approx 2$. Therefore, No. 2 breaks up the ranking, where the first and second positions present the collective idea of those alternatives in the top position who presents the most appropriate and satisfactory alternatives.

In the same way, the element sorted in a bottom position can be calculated as follows:

$$
x=n \times 4 / 5 \text {, }
$$

where $n$ is the total number of the sorted alternatives. For instance, if $n=7$, then $x=7 \times 4 / 5=5.6 \approx 6$. Thus, No. 6 breaks up the ranking, where the sixth and seventh positions present the collective idea of those alternatives in the bottom position who presents the worst and most dissatisfactory alternatives.

Step 2: Score the two sorted alternative sets. In the top position and the bottom position, each position of the sorted alternative set is assigned a corresponding score.

The score in the top position can be calculated as follows: 1 corresponds to the last position, 2 corresponds to the next-to-first position, ..., and $x$ corresponds to the first position. Finally, the score of each alternative in the top position is totaled, and marked $D$. 
Similarly, the score in the bottom position can be calculated as follows: 1 corresponds to the first position, 2 corresponds to the next-to-last position, ..., and $x$ corresponds to the last position. Finally, the score of each alternative in the bottom position is totaled, and marked $E$.

Step 3: Determine the priority of each alternative.

The priority of each alternative, which can identify and achieve an optimal ranking scheme from the opinion of all the participants involved in the GDM process, can be obtained as follows:

$$
S_{i}=D_{i}-E_{i},
$$

where the higher the value $S_{i}$ is, the better the alternative is.

Based on the above statement, the evaluation flowchart of the proposed GDMCRM model is presented in Figure 1.

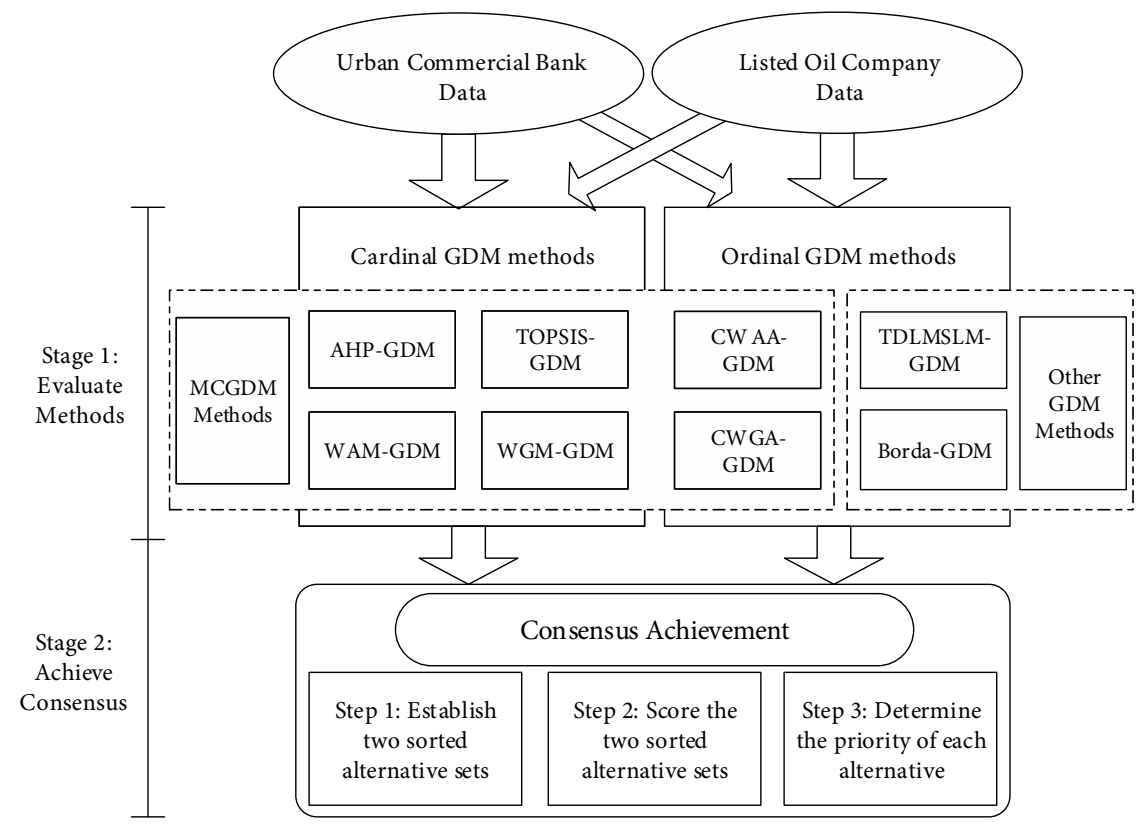

Figure 1. Evaluation flowchart of the proposed GDMCRM model

\section{Experimental study}

In this section, the proposed and developed GDMCRM model is tested and verified by two real-life datasets for demonstrating the effectiveness. Our focus is on performance evaluation of GDM methods based on group preferences under a multi-criteria environment, with the aim of reconciling different or even conflicting rankings.

\subsection{Datasets and index system}

In this subsection, two real-life datasets are applied to test and verify our proposed method in the experimental study. One dataset originates from the 2007 financial data of 12 urban commercial banks for credit risk analysis, these 12 urban commercial banks are the Bank of 
Hangzhou (BOHZ), Bank of Jiangsu (BOJS), Bank of Wenzhou (BOWZ), Bank of Shanghai (BOSH), Qilu Bank (QLB), Weihai City Commercial Bank (WHCCB), Fuzhou City Commercial Bank (FZCCB), Jiaxing City Commercial Bank (JXCCB), Huzhou City Commercial Bank (HZCCB), Bank of Taizhou (BOTZ), Bank of Nanchang (BONC), and Huishang Bank (HSB), belonging to six provinces and one city of Eastern China. The other dataset originates from the 2008 annual reports of seven listed oil companies, these seven listed oil companies are Exxon Mobil Corporation (XOM), China National Petroleum Corporation (CNPC), BP Amoco (BP), Royal Dutch/Shell Group of Companies (Shell), ConocoPhillips (CP), Chevron Corporation (CC), and Total. The hierarchy construction of these two datasets can be given in Table 1 and Table 2 respectively.

Table 1. Urban commercial bank credit risk index system

\begin{tabular}{|l|l|l|}
\hline \multirow{4}{*}{$\begin{array}{l}\text { Urban Commercial } \\
\text { Bank Credit Risk }\end{array}$} & Security (B1) & $\begin{array}{l}\text { Bad loan ratio (A1) } \\
\text { Core capital adequacy ratio (A2) }\end{array}$ \\
\cline { 2 - 3 } Index System (A) & Liquidity (B2) & $\begin{array}{l}\text { Current ratio (A3) } \\
\text { Loan-to-deposit ratio (A4) }\end{array}$ \\
\cline { 2 - 3 } & Profitability (B3) & $\begin{array}{l}\text { Return on equity (A5) } \\
\text { Earnings per share (A6) }\end{array}$ \\
\cline { 2 - 3 } & Development ability (B4) & $\begin{array}{l}\text { Deposit growth rate (A7) } \\
\text { Loan growth rate (A8) }\end{array}$ \\
\hline
\end{tabular}

Table 2. Listed oil company international competitiveness evaluation index system

\begin{tabular}{|c|c|c|}
\hline \multirow{6}{*}{$\begin{array}{l}\text { Listed Oil } \\
\text { Company } \\
\text { International } \\
\text { Competitiveness } \\
\text { Evaluation Index } \\
\text { System (A) }\end{array}$} & $\begin{array}{l}\text { Scale of } \\
\text { resources (B1) }\end{array}$ & $\begin{array}{l}\text { Total assets (millions of dollars) (C1) } \\
\text { Operating revenues (millions of dollars) (C2) } \\
\text { Oil and gas reserves (millions of barrels of oil equivalent (C3) } \\
\text { Oil and gas production (thousands of barrels of oil } \\
\text { equivalent) (C4) } \\
\text { Crude oil processing (volume/thousand barrels) (C5) }\end{array}$ \\
\hline & Profitability (B2) & $\begin{array}{l}\text { Net profit (millions of dollars) (C6) } \\
\text { Sales-to-profit ratio (C7) } \\
\text { Average return on capital (C8) } \\
\text { Return on equity (C9) } \\
\text { Return on total assets (C10) }\end{array}$ \\
\hline & $\begin{array}{l}\text { Management } \\
\text { Capacity (B3) }\end{array}$ & $\begin{array}{l}\text { Current ratio (C11) } \\
\text { Asset-to-liability ratio }(\mathrm{C} 12) \\
\text { Accounts receivable turnover ratio (C13) } \\
\text { Total asset turnover ratio (C14) } \\
\text { Per capita crude oil annual processing (volume/thousand } \\
\text { barrels) (C15) } \\
\text { Per capita profit (USD) (C16) }\end{array}$ \\
\hline & $\begin{array}{l}\text { Sustainable } \\
\text { Development } \\
\text { Capacity (B4) }\end{array}$ & $\begin{array}{l}\text { Total asset growth ratio }(\mathrm{C} 17) \\
\text { Reserve replacement ratio }(\mathrm{C} 18) \\
\text { Crude oil reserves and production ratio }(\mathrm{C} 19)\end{array}$ \\
\hline & $\begin{array}{l}\text { International } \\
\text { Business } \\
\text { Capacity (B5) }\end{array}$ & $\begin{array}{l}\text { Overseas oil and gas reserves ratio }(\mathrm{C} 20) \\
\text { Overseas oil and gas production ratio }(\mathrm{C} 21) \\
\text { Overseas investment ratio }(\mathrm{C} 22) \\
\text { Overseas profit ratio }(\mathrm{C} 23)\end{array}$ \\
\hline & \begin{tabular}{|l|} 
Market \\
Competitiveness \\
Capacity (B6)
\end{tabular} & $\begin{array}{l}\text { Oil sales (thousand barrels/day) (C24) } \\
\text { Chemical product sales (C25) } \\
\text { Oil sales (C26) }\end{array}$ \\
\hline
\end{tabular}


And the data values of these two datasets are given in Table 3 and Table 4, respectively.

Table 3. Financial data values of urban commercial banks

\begin{tabular}{|l|c|c|c|c|c|c|c|c|}
\hline & A1 & A2 & A3 & A4 & A5 & A6 & A7 & A8 \\
\hline BOHZ & 0.84 & 7.11 & 64.83 & 68.33 & 30.30 & 0.97 & 35.00 & 43.04 \\
\hline BOJS & 1.82 & 7.30 & 55.82 & 67.00 & 19.34 & 0.28 & 23.00 & 26.00 \\
\hline BOWZ & 1.45 & 7.43 & 52.61 & 72.96 & 25.89 & 0.46 & 20.98 & 19.46 \\
\hline BOSH & 2.23 & 9.11 & 38.21 & 63.58 & 16.33 & 1.18 & 32.48 & 37.01 \\
\hline QLB & 2.55 & 9.76 & 60.45 & 63.42 & 15.36 & 0.23 & 40.33 & 12.62 \\
\hline WHCCB & 1.60 & 10.53 & 64.41 & 72.00 & 2.79 & 0.03 & 25.15 & 18.79 \\
\hline FZCCB & 2.32 & 11.23 & 42.48 & 64.60 & 23.66 & 0.48 & 4.29 & 7.30 \\
\hline JXCCB & 1.76 & 9.03 & 45.49 & 71.65 & 13.52 & 0.24 & 18.57 & 25.19 \\
\hline HZCCB & 1.43 & 8.85 & 72.33 & 68.29 & 24.48 & 0.41 & 19.74 & 16.67 \\
\hline BOTZ & 0.43 & 10.77 & 54.85 & 67.08 & 42.35 & 0.66 & 34.54 & 28.73 \\
\hline BONC & 2.87 & 8.77 & 51.09 & 61.08 & 12.79 & 0.20 & 27.64 & 14.88 \\
\hline HSB & 1.22 & 13.61 & 39.44 & 71.32 & 21.56 & 0.15 & 26.19 & 37.99 \\
\hline
\end{tabular}

Table 4. Data values of listed oil companies

\begin{tabular}{|l|c|c|c|c|c|c|c|}
\hline & XOM & NCPC & BP & Shell & CP & CC & Total \\
\hline C1 & 228052 & 263989 & 228238 & 282401 & 142865 & 161165 & 166343 \\
\hline C2 & 477359 & 186239 & 365700 & 458361 & 246182 & 264958 & 225425 \\
\hline C3 & 26872 & 28344 & 18147 & 12249 & 10000 & 11200 & 10458 \\
\hline C4 & 3921 & 3829 & 3838 & 3170 & 2234 & 2530 & 2341 \\
\hline C5 & 5416 & 2727 & 6447 & 3388 & 2416 & 1858 & 2362 \\
\hline C6 & 45220 & 13408 & 21666 & 26476 & 16998 & 23931 & 19572 \\
\hline C7 & 9.84 & 7.2 & 6 & 5.78 & 0 & 9.03 & 8.72 \\
\hline C8 & 34.2 & 16.59 & 22 & 18.3 & 21.32 & 26.6 & 26 \\
\hline C9 & 38.5 & 5.6 & 23.2 & 20.78 & 0 & 29.23 & 22.9 \\
\hline C10 & 19.24 & 5.55 & 9.33 & 9.59 & 0 & 15.44 & 9.45 \\
\hline C11 & 147 & 129 & 95.11 & 110.46 & 95.7 & 114 & 137.09 \\
\hline C12 & 50.46 & 6.89 & 59.6 & 54.36 & 33 & 46.23 & 57.78 \\
\hline C13 & 15.03 & 28.25 & 10.87 & 5.87 & 18.83 & 13.83 & 10.43 \\
\hline C14 & 1.96 & 1.41 & 1.58 & 1.66 & 1.5 & 1.71 & 1.55 \\
\hline C15 & 24.4 & 0.61 & 25.22 & 11.95 & 25.73 & 10.78 & 8.8 \\
\hline C16 & 565957 & 8380 & 235500 & 259568 & 0 & 385984 & 201858 \\
\hline C17 & 5.80 & 8.07 & 3.3 & 4.8 & 19.63 & 8.32 & 4.2 \\
\hline C18 & 110 & 186 & 121 & 82.64 & 87.7 & 146.44 & 112 \\
\hline C19 & 16.3 & 17.9 & 12.45 & 11.6 & 9.38 & 10.71 & 12 \\
\hline C20 & 81.48 & 32.03 & 91 & 81.93 & 61 & 65.29 & 78 \\
\hline
\end{tabular}


End of Table 4

\begin{tabular}{|l|c|c|c|c|c|c|c|}
\hline & XOM & NCPC & BP & Shell & CP & CC & Total \\
\hline C21 & 72.34 & 28.17 & 87.9 & 77.84 & 70.64 & 73.48 & 73.69 \\
\hline C22 & 79.07 & 6.03 & 82.7 & 78.75 & 62.76 & 68.5 & 70 \\
\hline C23 & 83.8 & 7.96 & 91.64 & 68.88 & 56 & 66.84 & 77.53 \\
\hline C24 & 6761 & 1931 & 5698 & 6568 & 3040 & 3702 & 3658 \\
\hline C25 & 24982 & 15809 & 13360 & 20327 & 12775 & 19775 & 19650 \\
\hline C26 & 124.83 & 104.7 & 153.54 & 174.6 & 126.93 & 199 & 140.48 \\
\hline
\end{tabular}

\subsection{Empirical process}

In this subsection, two real-life datasets-urban commercial bank data and listed oil company data-are applied to test and verify our proposed method. Three experts from the field of risk assessment, including a risk-preference expert, a risk-averse expert and a risk-neutral expert, are selected and invited. According to their authority, experience, expertise, and risk preference, the weights of the three experts are $0.5,0.3$, and 0.2 , respectively. The empirical process is described and presented as follows:

In Stage 1, eight GDM methods, including four cardinal GDM methods and four ordinal GDM methods, are applied to evaluate and analyze these two datasets. The evaluation results, calculated by the steps of the eight GDM methods outlined in Section 3, for the urban commercial bank data are shown in Table 7, and the evaluation results for the listed oil company data are shown in Table 8. The graphic visualization comparison analysis is further carried out to make it easier to understand. The results presented in Figure 2 and Figure 3, show that the ranks of eight GDM methods are different and even conflicting rankings, and there is no regular pattern.

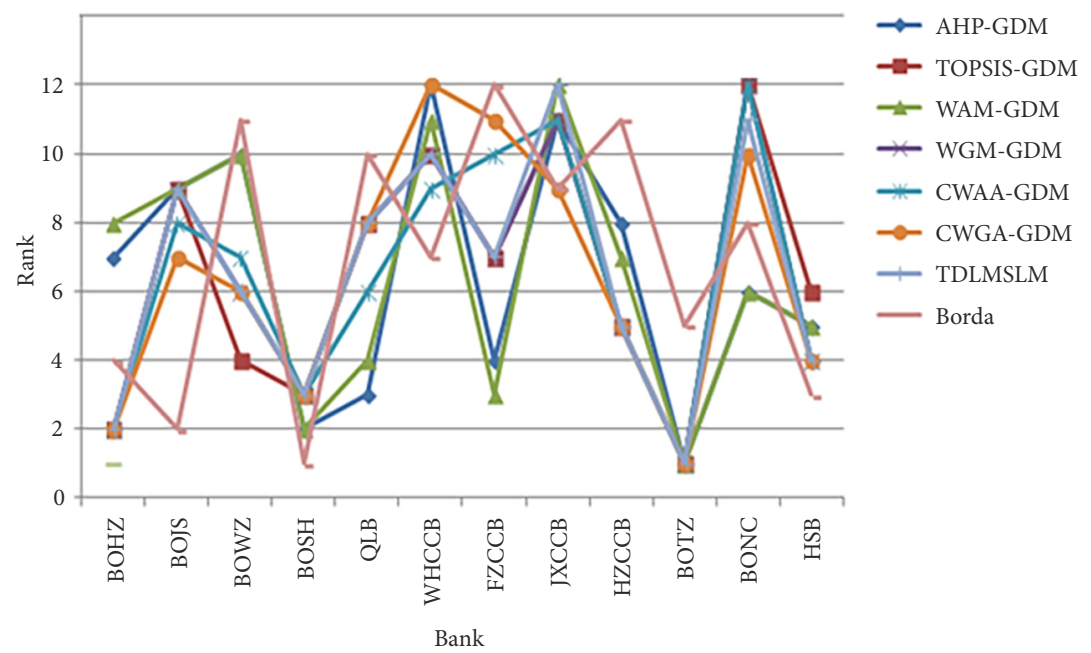

Figure 2. Ranks of eight GDM methods for urban commercial bank 


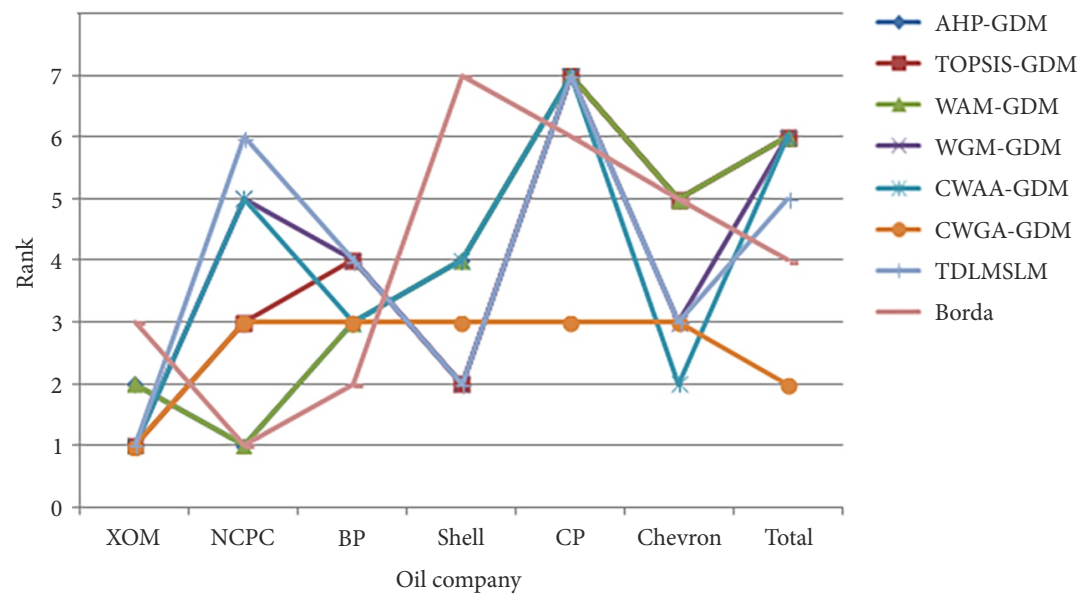

Figure 3. Ranks of eight GDM methods for listed oil company

It is noted that when using AHP for group decision making, the scores of hierarchy construction from expert opinions for urban commercial bank data are presented in Table 1-21 in the Supplementary material, and the scores of hierarchy construction for listed oil company data are presented in Table $22-48$ in the Supplementary material. In addition, the index weights and consistency test are also given respectively in the Supplementary material. For understanding, the index weights by each expert are presented in Table 5 for urban commercial bank data and in Table 6 for listed oil company data. The index weights obtained by AHP are used as input criteria weights of the MCGDM methods.

Table 5. Weights obtained by AHP of each expert for urban commercial bank data

\begin{tabular}{|l|c|c|c|c|c|c|c|c|}
\hline \multicolumn{1}{|c|}{ Weights } & C1 & C2 & C3 & C4 & C5 & C6 & C7 & C8 \\
\hline Expert 1 & 0.303 & 0.152 & 0.094 & 0.047 & 0.066 & 0.197 & 0.106 & 0.035 \\
\hline Expert 2 & 0.113 & 0.113 & 0.092 & 0.031 & 0.141 & 0.283 & 0.182 & 0.045 \\
\hline Expert 3 & 0.152 & 0.303 & 0.088 & 0.175 & 0.094 & 0.047 & 0.094 & 0.047 \\
\hline
\end{tabular}

Table 6. Weights obtained by AHP of each expert for listed oil company data

\begin{tabular}{|c|c|c|c|}
\hline Weights & Expert 1 & Expert 2 & Expert 3 \\
\hline C1 & 0.126 & 0.043 & 0.012 \\
\hline C2 & 0.052 & 0.028 & 0.022 \\
\hline C3 & 0.086 & 0.016 & 0.022 \\
\hline C4 & 0.028 & 0.016 & 0.012 \\
\hline C5 & 0.028 & 0.009 & 0.006 \\
\hline C6 & 0.081 & 0.071 & 0.023 \\
\hline C7 & 0.037 & 0.044 & 0.023 \\
\hline C8 & 0.057 & 0.014 & 0.046 \\
\hline
\end{tabular}


End of Table 6

\begin{tabular}{|c|c|c|c|}
\hline Weights & Expert 1 & Expert 2 & Expert 3 \\
\hline C9 & 0.022 & 0.044 & 0.023 \\
\hline C10 & 0.012 & 0.026 & 0.046 \\
\hline C11 & 0.015 & 0.023 & 0.056 \\
\hline C12 & 0.006 & 0.014 & 0.017 \\
\hline C13 & 0.009 & 0.008 & 0.033 \\
\hline C14 & 0.003 & 0.008 & 0.018 \\
\hline C15 & 0.014 & 0.036 & 0.033 \\
\hline C16 & 0.021 & 0.023 & 0.082 \\
\hline C17 & 0.028 & 0.032 & 0.030 \\
\hline C18 & 0.128 & 0.019 & 0.015 \\
\hline C19 & 0.053 & 0.010 & 0.03 \\
\hline C20 & 0.055 & 0.044 & 0.108 \\
\hline C21 & 0.038 & 0.086 & 0.108 \\
\hline C22 & 0.009 & 0.044 & 0.033 \\
\hline C23 & 0.024 & 0.141 & 0.061 \\
\hline C24 & 0.041 & 0.086 & 0.028 \\
\hline C25 & 0.020 & 0.086 & 0.057 \\
\hline C26 & 0.007 & 0.029 & 0.056 \\
\hline
\end{tabular}

In Stage 2, a CRM model, based on the 80-20 rule, is proposed to identify and achieve an optimal ranking scheme in order to reconcile different or even conflicting rankings generated by eight GDM methods. In order to facilitate analysis, the results of rankings of GDM methods for urban commercial bank data and for listed Oil Company data need to be transformed as shown in Tables 9 and 10, respectively.

The CRM model includes three steps:

Step 1: two scored alternative sets considered as a top position and a bottom position are established according to formulas (15) and (16), presented in bold typeface in Tables 9 and 10 .

Step 2: the scores for these two scored alternative sets are provided respectively by the principle presented in Section 4. The score of each alternative in the top position $D_{i}$ is totaled, and the score of each alternative in the bottom position $E_{i}$ is also totaled, and the results are presented in Table 11 for urban commercial bank data and Table 12 for listed oil company data.

Step 3: the priority of each alternative can be computed using formula (17), and the results are showed and presented in Tables 11 and 12, respectively. 


\begin{tabular}{|c|c|c|c|c|c|c|c|c|c|c|c|c|c|}
\hline \multirow{2}{*}{$\begin{array}{l}\tilde{Z} \\
\tilde{0} \\
\infty\end{array}$} & 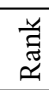 & 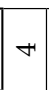 & $\sim$ & $\exists$ & -1 & 이 & $\wedge$ & $\simeq$ & $a$ & $\exists$ & in & $\infty$ & $m$ \\
\hline & $\frac{\mathscr{\Xi}}{\stackrel{\pi}{J}}$ & $\underset{\sim}{\stackrel{\sharp}{\sim}}$ & શิ & $\exists$ & $\stackrel{2}{\curvearrowright}$ & $\stackrel{2}{\Omega}$ & 응 & & $\stackrel{\sim}{2}$ & F & $\begin{array}{l}\infty \\
-\end{array}$ & $\infty$ & 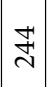 \\
\hline \multirow{2}{*}{ 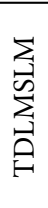 } & 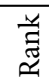 & $v$ & $a$ & 6 & $m$ & $\infty$ & 이 & $\wedge$ & $\simeq$ & in & -1 & $=$ & 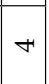 \\
\hline & $\frac{\mathscr{g}}{\tilde{J}}$ & 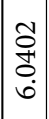 & $\begin{array}{l}\text { oे } \\
\text { ơ } \\
\hat{1}\end{array}$ & $\begin{array}{l}20 \\
0 \\
0 \\
\infty \\
-1\end{array}$ & $\begin{array}{l}r \\
\hat{o} \\
0 \\
\alpha \\
\alpha\end{array}$ & $\begin{array}{l}\infty \\
0 \\
0 \\
0 \\
0 \\
0\end{array}$ & $\begin{array}{l}-\overrightarrow{0} \\
0 \\
\dot{0} \\
\dot{m}\end{array}$ & $\begin{array}{l}\hat{\tilde{O}} \\
\text { o. } \\
\text { a }\end{array}$ & $\begin{array}{c}= \\
\vec{z} \\
\dot{\jmath} \\
\dot{m}\end{array}$ & $\begin{array}{l}0 \\
0 \\
0 \\
\infty \\
\infty \\
-1\end{array}$ & $\begin{array}{c}-7 \\
0 \\
0 \\
\text { in } \\
\text { in }\end{array}$ & 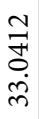 & 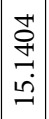 \\
\hline \multirow{2}{*}{ 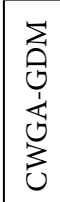 } & 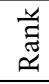 & 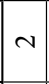 & $\curvearrowright$ & 0 & $m$ & $\infty$ & $\simeq$ & $=$ & $a$ & Ln & -1 & 으 & 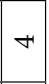 \\
\hline & $\frac{\mathscr{\Xi}}{\overbrace{\infty}^{\infty}}$ & $\begin{array}{c}m \\
\stackrel{m}{+} \\
\stackrel{0}{0}\end{array}$ & \begin{tabular}{l}
\multirow{3}{*}{} \\
\multirow{2}{0}{}
\end{tabular} & $\begin{array}{l}\overrightarrow{\tilde{O}} \\
\tilde{m} \\
0\end{array}$ & $\begin{array}{l}+1 \\
\hat{0} \\
0 \\
0 \\
0\end{array}$ & 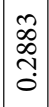 & 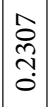 & 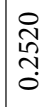 & 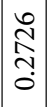 & 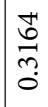 & $\begin{array}{l}0 \\
0 \\
0 \\
+ \\
0 \\
0\end{array}$ & 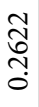 & $\begin{array}{c}\vec{z} \\
\vec{f} \\
\stackrel{m}{0}\end{array}$ \\
\hline \multirow{2}{*}{ 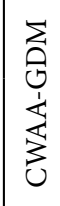 } & 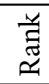 & $v$ & $\infty$ & $\wedge$ & $m$ & 0 & $a$ & 으 & $\exists$ & in & - & $\stackrel{\sim}{\simeq}$ & $r$ \\
\hline & $\frac{\mathscr{\Xi}}{\equiv}$ & $\begin{array}{l}\infty \\
1 \\
1 \\
1 \\
0 \\
0\end{array}$ & 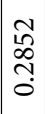 & 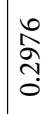 & $\begin{array}{l}2 \\
\text { oे } \\
+1 \\
0\end{array}$ & $\begin{array}{c}0 \\
0 \\
0 \\
0 \\
0\end{array}$ & 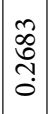 & $\begin{array}{l}\stackrel{2}{0} \\
\stackrel{\sim}{0}\end{array}$ & 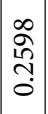 & $\begin{array}{l}0 \\
\stackrel{0}{n} \\
0\end{array}$ & $\mid \begin{array}{c}\infty \\
\stackrel{1}{n} \\
0 \\
0 \\
0\end{array}$ & 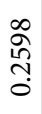 & $\begin{array}{c}\bar{n} \\
\hat{n} \\
n \\
0\end{array}$ \\
\hline \multirow{2}{*}{$\begin{array}{l}\sum_{1} \\
\text { Oئ } \\
\sum_{0}^{1} \\
3\end{array}$} & 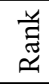 & $\sim$ & $a$ & 0 & $m$ & $\infty$ & 의 & $\wedge$ & $=$ & in & - & $\simeq$ & $r$ \\
\hline & $\frac{\mathscr{\Xi}}{\bar{J}}$ & $\begin{array}{c}\stackrel{0}{2} \\
\stackrel{1}{2} \\
\stackrel{0}{0}\end{array}$ & $\begin{array}{l}2 \\
\hat{\sigma} \\
0 \\
0\end{array}$ & 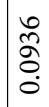 & $\begin{array}{l}\infty \\
\infty \\
\infty \\
\stackrel{0}{0} \\
0\end{array}$ & $\begin{array}{c}\overrightarrow{0} \\
0 \\
0 \\
0 \\
0\end{array}$ & \begin{tabular}{l}
\multirow{H}{*}{} \\
$\stackrel{0}{0}$ \\
$\dot{0}$
\end{tabular} & $\begin{array}{l}\stackrel{n}{0} \\
0 \\
0 \\
0 \\
0\end{array}$ & $\begin{array}{l}10 \\
0 \\
0 \\
0 \\
0\end{array}$ & $\begin{array}{l}F \\
\text { Fo } \\
\text { o }\end{array}$ & 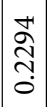 & $\begin{array}{l}m \\
0 \\
0 \\
0 \\
0\end{array}$ & $\begin{array}{c}2 \\
8 \\
0 \\
0\end{array}$ \\
\hline \multirow{2}{*}{ 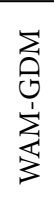 } & 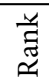 & $\infty$ & $a$ & 으 & 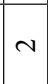 & $H$ & $\exists$ & $m$ & $\simeq$ & $\wedge$ & - & 0 & in \\
\hline & $\frac{\mathscr{\Xi}}{\overbrace{}^{ \pm}}$ & $\begin{array}{c}0 \\
\infty \\
\infty \\
0 \\
0 \\
0\end{array}$ & $\begin{array}{l}\stackrel{+}{J} \\
0 \\
0 \\
0\end{array}$ & $\begin{array}{l}m \\
\tilde{o} \\
0 \\
0\end{array}$ & $\begin{array}{l}1 \\
0 \\
0 \\
0 \\
0\end{array}$ & $\begin{array}{l}0 \\
0 \\
0 \\
0 \\
0\end{array}$ & $\begin{array}{l}\infty \\
\infty \\
0 \\
0 \\
0\end{array}$ & $\begin{array}{l}\overrightarrow{0} \\
0 \\
0 \\
0\end{array}$ & $\begin{array}{l}\mathfrak{2} \\
\hat{0} \\
0 \\
0\end{array}$ & $\begin{array}{l}m \\
\tilde{O} \\
0 \\
0 \\
0\end{array}$ & $\mid \begin{array}{l}0 \\
6 \\
0 \\
0 \\
0\end{array}$ & $\begin{array}{l}\stackrel{+}{+} \\
\infty \\
0 \\
0\end{array}$ & $\begin{array}{l}0 \\
\hat{n} \\
0 \\
0 \\
0\end{array}$ \\
\hline \multirow{2}{*}{$\begin{array}{l}\sum_{1} \\
0 \\
\vdots \\
\omega \\
\tilde{n} \\
0 \\
0\end{array}$} & 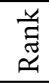 & $N$ & $a$ & 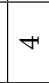 & $m$ & $\infty$ & $\stackrel{ }{ }$ & $\Lambda$ & $\exists$ & in & - & $\asymp$ & 0 \\
\hline & $\frac{\mathscr{g}}{\tilde{J}}$ & $\begin{array}{l}\infty \\
0 \\
\infty \\
10 \\
0 \\
0\end{array}$ & 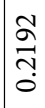 & $\begin{array}{l}\text { से } \\
\text { ñ } \\
0\end{array}$ & 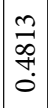 & 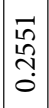 & $\begin{array}{l}\tilde{2} \\
\infty \\
\stackrel{1}{0}\end{array}$ & 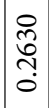 & \begin{tabular}{l}
$\infty$ \\
$\infty$ \\
$\infty$ \\
\hdashline \\
0
\end{tabular} & 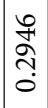 & $\mid \begin{array}{c}\stackrel{8}{+} \\
\stackrel{+}{+} \\
\dot{0}\end{array}$ & $\begin{array}{c}\infty \\
\stackrel{1}{+} \\
\stackrel{0}{0} \\
\stackrel{0}{0}\end{array}$ & 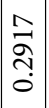 \\
\hline \multirow{2}{*}{ 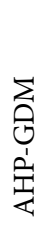 } & $\begin{array}{l}\text { 节 } \\
\text { ฯ }\end{array}$ & $\wedge$ & $a$ & 으 & $\sim$ & $m$ & 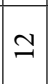 & $\theta$ & $=$ & $\infty$ & -1 & 0 & in \\
\hline & $\frac{\mathscr{\Xi}}{\frac{J}{\nu}}$ & $\mid \begin{array}{c}0 \\
\Delta \\
0 \\
0 \\
0\end{array}$ & $\begin{array}{l}0 \\
\stackrel{2}{2} \\
0 \\
0 \\
0\end{array}$ & $\begin{array}{l}\tilde{S} \\
\tilde{S} \\
0 \\
0\end{array}$ & 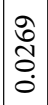 & $\begin{array}{l}\hat{O} \\
\tilde{D} \\
\dot{0}\end{array}$ & $\begin{array}{l}0 \\
\stackrel{1}{1} \\
\vdots \\
0 \\
0\end{array}$ & $\begin{array}{l}0 \\
0 \\
0 \\
0 \\
0\end{array}$ & \begin{tabular}{l}
$\mathbb{Z}$ \\
\multirow{O}{*}{} \\
0 \\
0
\end{tabular} & 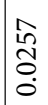 & $\mid \begin{array}{l}0 \\
\stackrel{2}{0} \\
0 \\
0\end{array}$ & $\begin{array}{l}0 \\
\dot{0} \\
0 \\
0 \\
0\end{array}$ & 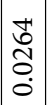 \\
\hline & & 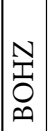 & $\stackrel{n}{0}$ & ${ }_{0}^{N}$ & $\begin{array}{l}\mathbb{T} \\
\tilde{D} \\
0 \\
\infty\end{array}$ & $\stackrel{\mathscr{a}}{\partial}$ & $\begin{array}{l}\infty \\
0 \\
ن \\
3 \\
3 \\
3\end{array}$ & 柋 & $\begin{array}{l}0 \\
\mathcal{u} \\
\underline{x} \\
\underline{x}\end{array}$ & 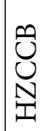 & $\begin{array}{l}N \\
0 \\
0 \\
\infty\end{array}$ & 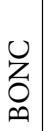 & $\begin{array}{l}\approx \\
\hat{\Xi} \\
\end{array}$ \\
\hline
\end{tabular}

\begin{tabular}{|c|c|c|c|c|c|c|c|c|}
\hline \multirow{2}{*}{ 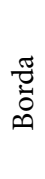 } & $\begin{array}{l}\text { 节 } \\
\text { ح }\end{array}$ & $m$ & - & $\sim$ & $\Lambda$ & 0 & in & $H$ \\
\hline & 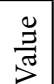 & $\stackrel{\Xi}{\sim}$ & $\vec{n}$ & $\stackrel{m}{n}$ & $\stackrel{20}{-}$ & $\approx$ & $\overrightarrow{6}$ & $\stackrel{1}{\circ}$ \\
\hline \multirow{2}{*}{ 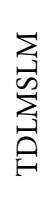 } & $\begin{array}{l}\text { त् } \\
\text { ح }\end{array}$ & - & 0 & 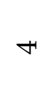 & $\sim$ & $\wedge$ & $m$ & in \\
\hline & $\stackrel{0}{\Xi}$ & $\begin{array}{l}\vec{\delta} \\
\delta \\
\dot{r}\end{array}$ & 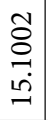 & 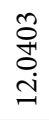 & \begin{tabular}{l} 
ơ \\
\multirow{0}{0}{} \\
$\stackrel{0}{ }$
\end{tabular} & $\begin{array}{l}\hat{O} \\
\text { O̦ } \\
\stackrel{i}{\dot{d}}\end{array}$ & $\begin{array}{l}\text { L } \\
0 \\
0 \\
0 \\
0\end{array}$ & 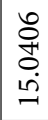 \\
\hline \multirow{2}{*}{ 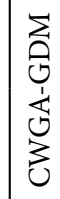 } & 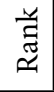 & - & $m$ & $m$ & $m$ & $m$ & $m$ & $N$ \\
\hline & 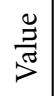 & 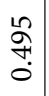 & $\begin{array}{l}8 \\
\vdots \\
\vdots\end{array}$ & \&̊ & $\begin{array}{l}8 \\
8 \\
\circ\end{array}$ & $\begin{array}{l}8 \\
\vdots \\
\vdots\end{array}$ & \begin{tabular}{l}
8 \\
\hdashline \\
$\dot{0}$
\end{tabular} & ஸे \\
\hline \multirow{2}{*}{ 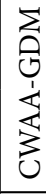 } & 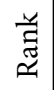 & - & 10 & $m$ & $r$ & $\wedge$ & $N$ & 0 \\
\hline & 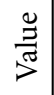 & 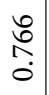 & 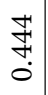 & \begin{tabular}{l}
$\pi$ \\
\multirow{0}{0}{} \\
0
\end{tabular} & $\begin{array}{l}\stackrel{2}{~} \\
\stackrel{+}{0} \\
0\end{array}$ & 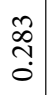 & $\begin{array}{l}\overrightarrow{0} \\
\text { nn } \\
0\end{array}$ & 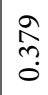 \\
\hline \multirow{2}{*}{$\begin{array}{l}\sum_{0} \\
0 \\
\sum_{0}^{1} \\
3\end{array}$} & $\begin{array}{l}\text { तै } \\
\text { ๙ }\end{array}$ & - & 10 & $H$ & $\sim$ & $\curvearrowright$ & $n$ & 6 \\
\hline & $\frac{n}{3}$ & $\begin{array}{l}\stackrel{+}{\sim} \\
\stackrel{\sim}{0}\end{array}$ & $\stackrel{9}{\overrightarrow{0}}$ & $\begin{array}{l}\vec{n} \\
\overrightarrow{0}\end{array}$ & $\begin{array}{l}\frac{H}{2} \\
\stackrel{0}{0}\end{array}$ & $\begin{array}{l}n \\
\hat{0} \\
0 \\
0\end{array}$ & $\begin{array}{l}\text { f } \\
\stackrel{0}{0}\end{array}$ & $\stackrel{m}{=}$ \\
\hline \multirow{2}{*}{$\begin{array}{l}\sum_{1}^{1} \\
\sum_{3}^{1} \\
3\end{array}$} & 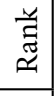 & $\sim$ & - & $m$ & $H$ & $\curvearrowright$ & in & 6 \\
\hline & $\frac{\mathscr{0}}{3}$ & $\begin{array}{l}0 \\
\text { לn } \\
0 \\
0\end{array}$ & $\begin{array}{l}\vec{n} \\
0 \\
0\end{array}$ & $\begin{array}{l}\stackrel{a}{0} \\
\dot{0}\end{array}$ & $\begin{array}{l}\infty \\
\text { + } \\
\dot{0}\end{array}$ & 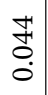 & fo & $\begin{array}{l}2 \\
0 \\
0 \\
0\end{array}$ \\
\hline \multirow{2}{*}{$\begin{array}{l}\sum_{1} \\
0 \\
\dot{1} \\
\omega \\
心 \\
0 \\
0 \\
1\end{array}$} & 䒕 & - & $m$ & 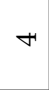 & $\sim$ & $\wedge$ & in & 6 \\
\hline & $\frac{0}{\frac{\Xi}{\pi}}$ & $\begin{array}{l}\stackrel{0}{\hat{\sigma}} \\
\stackrel{0}{0}\end{array}$ & 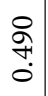 & $\underset{f}{\stackrel{f}{0}}$ & ণ্ণু & $\stackrel{\tilde{n}}{\tilde{\sigma}}$ & 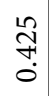 & $\underset{\tilde{m}}{\tilde{o}}$ \\
\hline \multirow{2}{*}{ 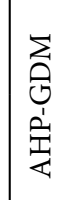 } & $\begin{array}{l}\ddot{y} \\
\widetilde{\pi}\end{array}$ & $\sim$ & - & $m$ & $H$ & $\wedge$ & in & 6 \\
\hline & 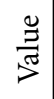 & $\begin{array}{l}0 \\
0 \\
0 \\
0\end{array}$ & $\begin{array}{l}\text { fे } \\
\text { Oे }\end{array}$ & $\begin{array}{l}\text { qu } \\
\text { O }\end{array}$ & 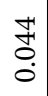 & $\begin{array}{l}\vec{F} \\
0 \\
0\end{array}$ & $\begin{array}{l}m \\
\text { O̦ } \\
0\end{array}$ & $\begin{array}{l}\text { I } \\
\text { : }\end{array}$ \\
\hline & & 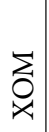 & $\begin{array}{l}0 \\
\text { z } \\
z\end{array}$ & $\stackrel{\rho}{\infty}$ & $\begin{array}{l}\overline{\bar{\Xi}} \\
\bar{\varpi}\end{array}$ & Өિ & $\begin{array}{l}\text { D } \\
\text { 苟 } \\
\text { J }\end{array}$ & 胥 \\
\hline
\end{tabular}


Table 9. Rankings of GDM methods for urban commercial bank data

\begin{tabular}{|c|l|l|l|l|l|l|l|l|}
\hline Rank & $\begin{array}{c}\text { AHP- } \\
\text { GDM }\end{array}$ & $\begin{array}{c}\text { TOPSIS- } \\
\text { GDM }\end{array}$ & $\begin{array}{c}\text { WAM- } \\
\text { GDM }\end{array}$ & $\begin{array}{c}\text { WGM- } \\
\text { GDM }\end{array}$ & $\begin{array}{c}\text { CWAA- } \\
\text { GDM }\end{array}$ & $\begin{array}{c}\text { CWGA- } \\
\text { GDM }\end{array}$ & $\begin{array}{c}\text { TDLMSLM- } \\
\text { GDM }\end{array}$ & $\begin{array}{c}\text { Borda- } \\
\text { GDM }\end{array}$ \\
\hline $\mathbf{1}$ & $\mathbf{B O T Z}$ & $\mathbf{B O T Z}$ & $\mathbf{B O T Z}$ & $\mathbf{B O T Z}$ & $\mathbf{B O T Z}$ & $\mathbf{B O T Z}$ & $\mathbf{B O T Z}$ & BOSH \\
\hline $\mathbf{2}$ & $\mathbf{B O S H}$ & $\mathbf{B O H Z}$ & $\mathbf{B O S H}$ & $\mathbf{B O H Z}$ & $\mathbf{B O H Z}$ & $\mathbf{B O H Z}$ & $\mathbf{B O H Z}$ & BOJS \\
\hline $\mathbf{3}$ & QLB & $\mathbf{B O S H}$ & FZCCB & $\mathbf{B O S H}$ & $\mathbf{B O S H}$ & $\mathbf{B O S H}$ & $\mathbf{B O S H}$ & HSB \\
\hline 4 & FZCCB & FZCCB & QLB & HSB & HSB & HSB & HSB & BOTZ \\
\hline 5 & HSB & HZCCB & HSB & HZCCB & HZCCB & HZCCB & HZCCB & BOHZ \\
\hline 6 & BONC & HSB & BONC & BOWZ & QLB & BOWZ & BOWZ & FZCCB \\
\hline 7 & BOHZ & FZCCB & HZCCB & FZCCB & BOWZ & BOJS & FZCCB & WHCCB \\
\hline 8 & HZCCB & QLB & BOHZ & QLB & BOJS & QLB & QLB & BONC \\
\hline 9 & BOJS & BOJS & BOJS & BOJS & WHCCB & JXCCB & BOJS & JXCCB \\
\hline $\mathbf{1 0}$ & BOWZ & WHCCB & BOWZ & WHCCB & FZCCB & BONC & WHCCB & QLB \\
\hline $\mathbf{1 1}$ & JXCCB & JXCCB & WHCCB & JXCCB & JXCCB & FZCCB & BONC & BOWZ \\
\hline $\mathbf{1 2}$ & WHCCB & BONC & JXCCB & BONC & BONC & WHCCB & JXCCB & HZCCB \\
\hline
\end{tabular}

Table 10. Rankings of GDM methods for listed oil company data

\begin{tabular}{|c|l|l|l|l|l|l|l|l|}
\hline Rank & $\begin{array}{c}\text { AHP- } \\
\text { GDM }\end{array}$ & $\begin{array}{c}\text { TOPSIS- } \\
\text { GDM }\end{array}$ & $\begin{array}{c}\text { WAM- } \\
\text { GDM }\end{array}$ & $\begin{array}{c}\text { WGM- } \\
\text { GDM }\end{array}$ & $\begin{array}{c}\text { CWAA- } \\
\text { GDM }\end{array}$ & $\begin{array}{c}\text { CWGA- } \\
\text { GDM }\end{array}$ & $\begin{array}{c}\text { TDLMSLM- } \\
\text { GDM }\end{array}$ & $\begin{array}{c}\text { Borda- } \\
\text { GDM }\end{array}$ \\
\hline $\mathbf{1}$ & NCPC & XOM & NCPC & XOM & XOM & XOM & XOM & NCPC \\
\hline $\mathbf{2}$ & XOM & Shell & XOM & Shell & CC & Total & Shell & BP \\
\hline 3 & BP & NCPC & BP & CC & BP & NCPC & CC & XOM \\
\hline 4 & Shell & BP & Shell & BP & Shell & Shell & BP & Total \\
\hline 5 & CC & CC & CC & NCPC & NCPC & BP & Total & CC \\
\hline $\mathbf{6}$ & Total & Total & Total & Total & Total & CP & NCPC & CP \\
\hline $\mathbf{7}$ & CP & CP & CP & CP & CP & CC & CP & Shell \\
\hline
\end{tabular}

Table 11. Priority of each alternative for urban commercial bank data

\begin{tabular}{|c|c|c|c|c|c|c|c|c|c|c|}
\hline Position & $1 \mathrm{st}$ & 2nd & $3 \mathrm{rd}$ & \multirow{2}{*}{$D_{i}$} & 10th & 11th & 12 th & \multirow{2}{*}{$E_{i}$} & \multirow{2}{*}{$F_{i}$} & \multirow{2}{*}{ Rank } \\
\hline Score & 3 & 2 & 1 & & 1 & 2 & 3 & & & \\
\hline $\mathrm{BOHZ}$ & & 5 & & 10 & & & & 0 & 10 & 3 \\
\hline BOJS & & 1 & & 2 & & & & 0 & 2 & 4 \\
\hline BOWZ & & & & 0 & 2 & 1 & & 4 & -4 & 9 \\
\hline $\mathrm{BOSH}$ & 1 & 2 & 5 & 12 & & & & 0 & 12 & 2 \\
\hline QLB & & & 1 & 1 & 1 & & & 1 & 0 & 6 \\
\hline WHCCB & & & & 0 & 3 & 1 & 2 & 11 & -11 & 10 \\
\hline FZCCB & & & 1 & 1 & 1 & 1 & & 3 & -2 & 7 \\
\hline JXCCB & & & & 0 & & 4 & 2 & 14 & -14 & 12 \\
\hline HZCCB & & & & 0 & & & 1 & 3 & -3 & 8 \\
\hline BOTZ & 7 & & & 21 & & & & 0 & 21 & 1 \\
\hline BONC & & & & 0 & 1 & 1 & 3 & 12 & -12 & 11 \\
\hline HSB & & & 1 & 1 & & & & 0 & 1 & 5 \\
\hline
\end{tabular}


Table 12. Priority of each alternative for listed oil company data

\begin{tabular}{|l|c|c|c|c|c|c|c|c|}
\hline Position & $1^{\text {st }}$ & 2nd & \multirow{2}{*}{$D_{i}$} & 6 th & 7th & \multirow{2}{*}{$E_{i}$} & \multirow{2}{*}{$F_{i}$} & \multirow{2}{*}{ Rank } \\
\cline { 1 - 1 } \multicolumn{1}{c}{ Score } & 2 & 1 & & 1 & 2 & & & \\
\hline XOM & 5 & 2 & 12 & & & 0 & 12 & 1 \\
\hline NCPC & 3 & & 6 & 1 & & 1 & 5 & 2 \\
\hline BP & & 1 & 2 & & & 0 & 2 & 3 \\
\hline Shell & & 3 & 3 & & 1 & 2 & 1 & 4 \\
\hline CP & & & 0 & 2 & 6 & 14 & -14 & 7 \\
\hline CC & & 1 & 1 & & 1 & 2 & -1 & 5 \\
\hline Total & & 1 & 1 & 5 & & 5 & -4 & 6 \\
\hline
\end{tabular}

\subsection{Experimental results and discussion}

In Table 11, we can obtain the credit risk rankings as 3, 4, 9, 2, 6, 10, 7, 12, 8, 1, 11, and 5, which is in line with the Bank of Hangzhou, Bank of Jiangsu, Bank of Wenzhou, Bank of Shanghai, Qilu Bank, Weihai City Commercial Bank, Fuzhou City Commercial Bank, Jiaxing City Commercial Bank, Huzhou City Commercial Bank, Taizhou Bank, Bank of Nanchang, and Huishang Bank, respectively. We also can see that the best credit among urban commercial banks is that of the Taizhou Bank, the second best is the Bank of Shanghai, and the third best is the Bank of Hangzhou, while the worst is Jiaxing City Commercial Bank, followed by the Bank of Nanchang, which is also consistent with the real banking industry. In Table 12, we can see that the priority of each alternative is $1,2,3,4,7,5$, and 6 , which is in line with XOM, CNPC, BP, Shell, ConocoPhillips, Chevron, and Total, respectively. The best international competitiveness of the listed oil companies is XOM, the second is NCPC, and the third is BP, while the worst is ConocoPhillips, which is also consistent with rankings reported by Petroleum Intelligence Weekly.

How to evaluate GDM methods for decision makers are a significant task and a challenging issue. In Stage 1 of the evaluation process, the ranks obtained by the eight GDM methods for the two datasets are different and even conflicting rankings, that is, no group decision-making method is perfect to satisfy every member of a group, which verifies the pointed out problem of Arrow's impossibility theorem for greatly expanding our theoretical significance and theoretical implication. In Stage 2, based on the consensus recognition model (CRM), the difference of performance evaluation among the eight GDM methods has gradually converged, and the results for urban commercial bank data and listed oil company data are in strong agreement with actual industry. The practical significance and implication is that the proposed GDMCRM model is developed to not only reconcile different and even conflicting rankings in GDM, but also to provide a new perspective for efficiently making consensus achievement among evaluation and selection of multiple methods. Besides, according to the 80-20 rule, the preferences of all the participants can be fully considered. The results show that the proposed method from managerial implication can largely satisfy the group preferences of all the stakeholders involved in the decision making process, which can lead to better decisions and improve business efficiency, especially in a complex decision making environment. 


\section{Conclusions}

The decision process has became increasingly more and more challenging due to the complexity of environments and expectations of multiple stakeholders, in addition to the quality and quantity of data. They can even lead to group conflict, affect group performance and reduce decision quality, since traditional assessment methods usually do not work for unclear responsibility, minority dictatorship, and discontented compromise. Arrow's impossibility theorem (1963) stated that no group decision making method is perfect. Furthermore, Modern social choice theory (Banerjee, 1994) shows that the result of group decision can never satisfy every member of the group. Therefore, how to evaluate GDM methods for decision makers are a significant task and a challenging problem. Besides, different GDM methods can produce different or even conflicting results. And how to reconcile different or conflicting rankings in GDM has not been fully investigated and researched. So the goal of this paper is to address these two issues.

This paper focuses on the evaluation of GDM methods based on group preferences under a multi-criteria environment with the aim of reconciling different or even conflicting rankings for identifying the best compromise solution from the opinion of all the participants involved in the GDM problem. The proposed GDMCRM model includes two stages: the first is to evaluate GDM methods under a multi-criteria environment, and the second is to identify and achieve an optimal ranking scheme by a consensus recognition model, named CRM. In Stage 1, by reading a significant amount of literature, six GDM methods under a multi-criteria environment are selected. In addition, two other GDM methods are presented to facilitate comparative analysis. Furthermore, both ordinal and cardinal GDM methods are considered in the evaluation of GDM methods under a multi-criteria environment, which further increases this research depth and scientific nature. In Stage 2, the CRM model is presented to reconcile different or even conflicting rankings generated by the eight GDM methods used in Stage 1. In this process, the 80-20 rule (Wu et al., 2020) is applied to focus on the most important positions of the rankings associated with the number of observations, and it can largely consider the most important group preferences of all the participants.

Finally, an experiment is analyzed to examine and verify the proposed model on two reallife datasets: an urban commercial bank dataset and a listed oil company dataset. The results show that the proposed GDMCRM model can serve as a practical technology for evaluating performance of GDM methods based on group preferences under a multi-criteria environment, as well as for reconciling different or even conflicting rankings, which can provide an optimal ranking scheme to make better decisions and improve business efficiency when the results from using different GDM techniques are in disagreement.

\section{Acknowledgements}

This research has been partially supported by Grants from Fund for Less Developed Regions of the National Natural Science Foundation of China (\#71761014), the General Program of National Natural Science Foundation of China (\#71471149), Major Project of the National Social Science Foundation of China (\#15ZDB153), Education Science "13TH FIVE-YEAR PLAN” Research Project of Guangdong Province (2020GXJK384), and Postdoctoral Science Foundation Project of China (\#2016M592683). 


\section{References}

Arrow, K. J. (1963). Social choice and individual values (2nd ed). Wiley.

Ascough II, J. C., Maier, H. R., Ravalico, J. K., \& Strudley, M. W. (2008). Future research challenges for incorporation of uncertainty in environmental and ecological decision-making. Ecological Modelling, 219(3-4), 383-399. https://doi.org/10.1016/j.ecolmodel.2008.07.015

Banerjee, A. (1994). Fuzzy preferences and Arrow-type problems. Social Choice and Welfare, 11(1), 121-130. https://doi.org/10.1007/bf00179208

Benjamin, R. (2002). Social choice in the South Seas: electoral innovation and the Borda count in the pacific Island countries. International Political Science Review, 23(4), 355-372. https://doi.org/10.1177/0192512102023004002

Beynon, M. J. (2005). A method of aggregation in DS/AHP for group decision-making with the non-equivalent importance of individuals in the group. Computers \& Operations Research, 32(7), 1881-1896. https://doi.org/10.1016/j.cor.2003.12.004

Blanco-Mesa, F., León-Castro, E., Merigó, J. M., \& Xu, Z. S. (2019). Bonferroni means with induced ordered weighted average operators. International Journal of Intelligent Systems, 34(1), 3-23. https://doi.org/10.1002/int.22033

Chang, K. H., \& Cheng, C. H. (2011). Evaluating the risk of failure using the fuzzy OWA and DEMATEL method. Journal of Intelligent Manufacturing, 22(2), 113-129. https://doi.org/10.1007/s10845-009-0266-X

Chatterjee, N. C., \& Bose, G. K. (2013). A COPRAS-F base multi-criteria group decision making approach for site selection of wind farm. Decision Science Letters, 2(1), 1-10. https://doi.org/10.5267/j.dsl.2012.11.001

Chen, S. J., \& Hwang, C. L. (1992). Fuzzy multiple attribute decision making: methods and applications. Springer-Verlag. https://doi.org/10.1007/978-3-642-48318-9

Chiclana, F., Herrera, F., \& Herrera-Viedma, E. (2000). The ordered weighted geometric operator: properties and application. In Proceedings of the 8th International Conference on Information Processing and Management of Uncertainty in Knowledge-Based Systems (pp. 985-991). Madrid, Spain. https://doi.org/10.1007/978-3-7908-1796-6_14

Chiclana, F., Herrera-Viedma, E., Herrera, F., \& Alonso, S. (2007). Some induced ordered weighted averaging operators and their use for solving group decision-making problems based on fuzzy preference relations. European Journal of Operational Research, 182(1), 383-399. https://doi.org/10.1016/j.ejor.2006.08.032

Chwolka, A., \& Raith, M. G. (2001). Group preference aggregation with the AHP implications for multiple-issue agendas. European Journal of Operational Research, 132(1), 176-186. https://doi.org/10.1016/S0377-2217(00)00121-1

Cutello, V., \& Montero, J. (1994). Hierarchies of aggregation operators. International Journal of Intelligent Systems, 9(11), 1025-1045. https://doi.org/10.1002/int.4550091104

Dong, Y. C., Zha, Q. B., Zhang, H. J., Kou, G., Fujita, H., Chiclana, F., \& Herrera-Viedma, E. (2018). Consensus reaching in social network group decision making: Research paradigms and challenges. Knowledge-Based Systems, 162, 3-13. https://doi.org/10.1016/j.knosys.2018.06.036

Dong, Y, C., Zhang, G. Q., Hong, W. C., \& Xu, Y. F. (2010). Consensus models for AHP group decision making under row geometric mean prioritization method. Decision Support Systems, 49(3), 281-289. https://doi.org/10.1016/j.dss.2010.03.003

Emerson, P. (2007). Designing an all-inclusive democracy-consensual voting procedures for use in parliaments, councils and committees. Springer-Verlag Berlin Heidelberg.

Filho, J. L. E. S., \& Morais, D. C. (2018). Group decision model based on ordered weighted distance to aid decisions on logistics. International Journal of Uncertainty, Fuzziness and Knowledge-Based Systems, 26(2), 233-254. https://doi.org/10.1142/S0218488518500125 
Franz, B. (1936). Pareto. John Wiley \& Sons.

Fu, G. T. (2008). A fuzzy optimization method for multi-criteria decision making: an application to reservoir flood control operation. Expert Systems with Applications, 31(1), 145-149. https://doi.org/10.1016/j.eswa.2006.08.021

Gargallo, P., Moreno-Jiménez, J. M., \& Salvador, M. (2007). AHP-group decision making: a Bayesian approach based on mixtures for group pattern identification. Group Decision and Negotiation, 16, 485-506. https://doi.org/10.1007/s10726-006-9068-0

Glasser, W. (1998). Choice theory: a new psychology of personal freedom. Harper Perennial, 9(1), 72-75. https://doi.org/10.1098/rsnr.2002.0171

Gou, X. J., Xu, Z. S., Liao, H. C., \& Herrera, F. (2018). Multiple criteria decision making based on distance and similarity measures under double hierarchy hesitant fuzzy linguistic environment. Computers \& Industrial Engineering, 126, 516-530. https://doi.org/10.1016/j.cie.2018.10.020

Hwang, C. L., \& Yoon, K. (1981). Multiple attribute decision making. Springer Berlin Heidelberg. https://doi.org/10.1007/978-3-642-48318-9

Ishizaka, A., \& Labib, A. (2011). Review of the main developments in the analytic hierarchy process. Expert Systems with Application, 38, 14336-14345. https://doi.org/10.1016/j.eswa.2011.04.143

Jabbarzadeh, A. (2018). Application of the AHP and TOPSIS in project management. International Journal of Project Management, 3(2), 125-130. https://doi.org/10.5267/j.jpm.2018.1.001

Jahanshahloo, G. R., Lotfi Hosseinzadeh, F., \& Izadikhah, M. (2006). Extension of the TOPSIS method for decision-making problems with fuzzy data. Applied Mathematics and Computation, 181(2), 1544-1551. https://doi.org/10.1016/j.amc.2006.02.057

Jung, C., Lee, H., Lim, Y., \& Yamazaki, K. (2010). Weighted geometric mean of n-operators with nparameters. Linear Algebra and its Applications, 432(6), 1515-1530.

https://doi.org/10.1016/j.laa.2009.11.013

Kim, S. H., \& Ahn, B. S. (1997). Group decision-making procedure considering preference strength under incomplete information. Computer \& Operations Research, 24(12), 1101-1112. https://doi.org/10.1016/S0305-0548(97)00037-3

Kou, G., \& Ergu, D. J. (2016). AHP/ANP theory and its application in technological and economic development: the 90th anniversary of Thomas L. Saaty. Technological and Economic Development of Economy, 22(5), 649-650. https://doi.org/10.3846/20294913.2016.1202353

Kou, G., Lu, Y. Q., Peng, Y., \& Shi, Y. (2012). Evaluation of classification algorithms using MCDM and rank correlation. International Journal of Information Technology \& Decision Making, 11(1), 197-225. https://doi.org/10.1142/S0219622012500095

Kwok, R. C., Ma, J., \& Zhou, D. N. (2002). Improving group decision making: a fuzzy GSS approach. IEEE Transactions on Systems, Man, and Cybernetics-Part C: Applications and Reviews, 32(1), 54-63. https://doi.org/10.1109/TSMCC.2002.1009142

Li, C. C., Dong, Y. C., Herrera, F., Herrera-Viedma, E., \& Martínez, L. (2017). Personalized individual semantics in computing with words for supporting linguistic group decision making. An application on consensus reaching. Information Fusion, 33, 29-40. https://doi.org/10.1016/j.inffus.2016.04.005

Li, J., Davies, G. J., Kendall, G., Soane, E., Bai, R., Rocks, S. A., \& Pollard, S. J. T. (2012). Evidence and belief in regulatory decisions-Incorporating expected utility into decision modeling. Expert Systems with Applications, 39(10), 8604-8610. https://doi.org/10.1016/j.eswa.2012.01.193

Liang, D. C., Xu, Z. S., Liu, D., \& Wu, Y. (2018). Method for three-way decisions using ideal TOPSIS solutions at Pythagorean fuzzy information. Information Sciences, 435, 282-295. https://doi.org/10.1016/j.ins.2018.01.015

Liao, H. C., Yang, L. Y., \& Xu, Z. S. (2018). Two new approaches based on ELECTRE II to solve the multiple criteria decision making problems with hesitant fuzzy linguistic term sets. Applied Soft Computing, 63, 223-234. https://doi.org/10.1016/j.asoc.2017.11.049 
Liu, W. Q., Dong, Y. C., Chiclana, F., Cabrerizo, F. J., \& Herrera-Viedma, E. (2017). Group decisionmaking based on heterogeneous preference relations with self-confidence. Fuzzy Optimization and Decision Making, 16, 429-447. https://doi.org/10.1007/s10700-016-9254-8

Ma, J., Lu, J., \& Zhang, G. Q. (2010). Decider: A fuzzy multi-criteria group decision support system. Knowledge-Based Systems, 23(1), 23-31. https://doi.org/10.1016/j.knosys.2009.07.006

Marichal, J. L. (2001). An axiomatic approach of the discrete Choquet integral as a tool to aggregate interacting criteria. IEEE Transactions on Fuzzy Systems, 8(6), 800-807. https://doi.org/10.1109/91.890347

Montserrat-Adell, J., Xu, Z. S., Gou, X. J., \& Agell, N. (2019). Free Double Hierarchy Hesitant Fuzzy Linguistic Term Sets: An application on ranking alternatives in GDM. Information Fusion, 47, 45-59. https://doi.org/10.1016/j.inffus.2018.07.002

Morais, D. C., \& Almeida, A. T. D. (2012). Group decision making on water resources based on analysis of individual rankings. Omega, 40(1), 42-52. https://doi.org/10.1016/j.omega.2011.03.005

Moreno-Jiménez, J. M., Aguarón, J., \& Escobar, M. T. (2008). The core of consistency in AHP-group decision making. Group Decision and Negotiation, 17(3), 249-265. https://doi.org/10.1007/s10726-007-9072-z

O'Hagan, M. (1998). Aggregating template or rule antecedents in real-time expert systems with fuzzy set logic. In Proceedings of the Twenty-Second Asilomar Conference on Signals, Systems and Computers (pp. 681-689), Pacific Grove, CA, USA. https://doi.org/10.1109/ACSSC.1988.754637

Olson, D. L. (2004). Comparison of weights in TOPSIS models. Mathematical and Computer Modeling, 40(7-8), 721-727. https://doi.org/10.1016/j.mcm.2004.10.003

Pang, J. F., \& Liang, J. Y. (2012). Evaluation of the results of multi-attribute group decision-making with linguistic information. Omega, 40(3), 294-301. https://doi.org/10.1016/j.omega.2011.07.006

Peng, Y., Kou, G., Wang, G. X., Wu, W. S., \& Shi, Y. (2011). Ensemble of software defect predictors: an AHP-based evaluation method. International Journal of Information Technology \& Decision Making, 10(1), 187-206. https://doi.org/10.1142/S0219622011004282

Pérez-Arellano, L. A., León-Castro, E., Avilés-Ochoa, E., \& Merigó, J. M. (2019). Prioritized induced probabilistic operator and its application in group decision making. International Journal of Machine Learning and Cybernetics, 10(3), 451-462. https://doi.org/10.1007/s13042-017-0724-2

Poulton, E. C. (1994). Behavioral decision theory: a new approach. Cambridge University Press. https://doi.org/10.1017/CBO9780511574894

Renato, C. (1983). Was Vilfredo Pareto really a 'precursor' of fascism? The American Journal of Economics and Sociology, 42(2), 235-245. https://doi.org/10.1111/j.1536-7150.1983.tb01708.x

Saaty, T. L. (1978). Modeling unstructured decision problems-the theory of analytical hierarchies. Mathematics and Computers in Simulation, 20(3), 147-158. https://doi.org/10.1016/0378-4754(78)90064-2

Saaty, T. L. (1979). Applications of analytical hierarchies. Mathematics and Computers in Simulation, 21(1), 1-20. https://doi.org/10.1016/0378-4754(79)90101-0

Saaty, T. L. (1986). Axiomatic foundation of the analytic hierarchy process. Management Science, 32(7), 841-855. https://doi.org/10.1287/mnsc.32.7.841

Saaty, T. L. (1990). How to make a decision: the analytic hierarchy process. European Journal of Operational Research, 48(1), 9-26. https://doi.org/10.1016/0377-2217(90)90057-I

Saaty, T. L. (2003). Decision-making with the AHP: Why is the principal eigenvector necessary? European Journal of Operational Research, 145(1), 85-91. https://doi.org/10.1016/S0377-2217(02)00227-8

Sen, A. K. (1970). Collective choice and social welfare. North-Holland. https://doi.org/10.1016/C2009-0-12011-1

Shen, F., Ma, X. S., Li, Z. Y., Xu, Z. S., \& Cai, D. L. (2018). An extended intuitionistic fuzzy TOPSIS method based on a new distance measure with an application to credit risk evaluation. Information Sciences, 428, 105-119. https://doi.org/10.1016/j.ins.2017.10.045 
Srdjevic, B. (2007). Linking analytic hierarchy process and social choice methods to support group decision-making in water management. Decision Support Systems, 42(4), 2261-2273. https://doi.org/10.1016/j.dss.2006.08.001

$\mathrm{Su}$, K. P., Zhou, L. G., \& Chen, H. Y. (2011). Portfolio decision making model with CWAA operator under CVaR measure. Journal of Wuhan University of Technology (Information \& Management Engineering), 33(4), 618-621.

Tang, J., \& Meng, F. Y. (2019). Linguistic intuitionistic fuzzy Hamacher aggregation operators and their application to group decision making. Granular Computing, 4(1), 109-124. https://doi.org/10.1007/s41066-018-0089-2

Von Neumann, J., \& Morgenstern, O. (1944). Theory of games and economic behavior. Princeton University Press.

Wang, Z. J., Wang, Y., \& Li, K. W. (2016). An acceptable consistency-based framework for group decision making with intuitionistic preference relations. Group Decision and Negotiation, 25(1), 181-202. https://doi.org/10.1007/s10726-015-9438-6

Wu, W. S. (2017). Grey relational analysis method for Group Decision Making in Credit Risk Analysis. EURASIA Journal of Mathematics Science and Technology Education, 13(12), 7913-7920. https://doi.org/10.12973/ejmste/77913

Wu, W. S., Kou, G., \& Peng, Y. (2018). A consensus facilitation model based on experts' weights for investment strategy selection. Journal of the Operational Research Society, 69(9), 1435-1444. https://doi.org/10.1080/01605682.2017.1398203

Wu, W. S., Kou, G., Peng, Y., \& Ergu, D. J. (2012). Improved AHP-group decision-making for investment strategy selection. Technological and Economic Development of Economy, 18(2), 299-316. https://doi.org/10.3846/20294913.2012.680520

Wu, W. S., \& Peng, Y. (2016). Extension of grey relational analysis for facilitating group consensus to oil spill emergency management. Annals of Operations Research, 238(1), 615-635. https://doi.org/10.1007/s10479-015-2067-2

Wu, W. S., Xu, Z. S., Kou, G., \& Shi, Y. (2020). Decision-making support for the evaluation of clustering algorithms based on MCDM. Complexity, 2020, 9602526. https://doi.org/10.1155/2020/9602526

Xian, S. D., Liu, Z., Gou, X. L., \& Wan, W. H. (2020). Interval 2-tuple Pythagorean fuzzy linguistic MULTIMOORA method with CIA and their application to MCGDM. International Journal of Intelligent Systems, 35(4), 650-681. https://doi.org/10.1002/int.22221

Xian, S. D., Xue, W. T., \& Jing, N. (2016). Fuzzy entropic ordered weighted averaging operator and its application in group decision making. International Journal of Intelligent Systems, 31(9), 872-885. https://doi.org/10.1002/int.21808

$\mathrm{Xu}$, J. P., \& Chen, J. Z. (2007). The theory and methods of group decision making with its realization. Tsinghua University Press.

Xu, J. P., \& Shen, F. (2014). A new outranking choice method for group decision making under Atanassov's interval-valued intuitionistic fuzzy environment. Knowledge-Based Systems, 70, 177-188. https://doi.org/10.1016/j.knosys.2014.06.023

$\mathrm{Xu}, \mathrm{Z}$. S. (2000). On consistency of the weighted geometric mean complex judgment matrix in AHP. European Journal of operational Research, 126(3), 683-687. https://doi.org/10.1016/S0377-2217(99)00082-X

Xu, Z. S., \& Da, Q. L. (2002a). The ordered weighted geometric averaging operator. International Journal of Intelligent Systems, 17(7), 709-716. https://doi.org/10.1002/int.10045

$\mathrm{Xu}, \mathrm{Z}$. S., \& Da, Q. L. (2002b). Combined weighted geometric averaging operator and its application. Journal of Southeast University (Natural Science Edition), 32(3), 506-509. 
Yager, R. (1993). Non-numeric multi-criteria multi-person decision making. Group Decision and Negotiation, 2, 81-93. https://doi.org/10.1007/bf01384404

Yager, R. R. (1988). On ordered weight averaging aggregation operators in multi-criteria decision making. IEEE Transactions on Systems, Man and Cybernetics, 18(1), 183-190. https://doi.org/10.1109/21.87068

Yager, R. R., Goldstein, L. S, \& Mendels, E. (1994). FUZMAR: An approach to aggregating market research data based on fuzzy reasoning. Fuzzy Sets and Systems, 68(1), 1-11. https://doi.org/10.1016/0165-0114(94)90269-0

Yan, H. B., \& Ma, T. J. (2015). A group decision-making approach to uncertain quality function deployment based on fuzzy preference relation and fuzzy majority. European Journal of Operational Research, 241(3), 815-829. https://doi.org/10.1016/j.ejor.2014.09.017

Yoon, K. P., \& Hwang, C. L. (1995). Multiple attribute decision making: an introduction. Sage Publications. https://doi.org/10.4135/9781412985161

Yu, C. S. (2002). A GP-AHP method for solving group decision-making fuzzy AHP problems. Computers \& Operations Research, 29(14), 1969-2001. https://doi.org/10.1016/S0305-0548(01)00068-5

Yue, Z. L. (2011). A method for group decision-making based on determining weights of decision makers using TOPSIS. Applied Mathematical Modelling, 35(4), 1926-1936. https://doi.org/10.1016/j.apm.2010.11.001

Yue, Z. L. (2014). TOPSIS-based group decision-making methodology in intuitionistic fuzzy setting. Information Sciences, 277, 141-153. https://doi.org/10.1016/j.ins.2014.02.013

Zhang, H. M. (2015). Group decision making based on multiplicative consistent reciprocal preference relations. Fuzzy Sets and Systems, 282, 31-46. https://doi.org/10.1016/j.fss.2015.04.009

Zhang, H. M. (2016). Group decision making based on incomplete multiplicative and fuzzy preference relations. Applied Soft Computing, 48, 735-744. https://doi.org/10.1016/j.asoc.2016.07.046 